\section{Modelo de clasificación y visualización de relaciones texto-imagen}

\section{Resumen}

El gran volumen de datos e información generado en la actualidad, ha obligado al uso de diferentes medios para lograr una mejor comunicación. Los más utilizados son el texto y la imagen, los cuales se relacionan por parte de su écfrasis, que es la representación verbal de una representación visual. Por tanto, el presente artículo se realiza con el fin de identificar relaciones texto-imagen (RTI), y propone un modelo de clasificación y visualización basada en el principio de similitud en su naturaleza, con el fin evitar la proliferación de RTI aisladas o independientes. Lo anterior se logra mediante una revisión y caracterización de fuentes que permiten hacer un análisis a las diferentes RTI, que se trabajan mediante técnicas documentales y análisis de información, permitiendo una clarificación y uso diferenciado. En el artículo se presentan diferentes RTI basadas en la realidad, el mensaje, lógico semánticas y de relevancia en cómics; igualmente, evidencia funciones de RTI, sus diferentes relaciones dialógicas y termina con las vías ilustrativas. Finalmente, se presentan los modelos de clasificación y representación $2 \mathrm{D}$ y $3 \mathrm{D}$ que permiten identificar clases, jerarquías y ubicación espacial de la estructura de las RTI. Dichos modelos de clasificación y representación son claves para la organización e interpretación objetiva de las RTI y textos, no solo por parte del lector, sino también de sistemas de cómputo para la extracción de características en contexto.
Andrés Esteban Menza Vados Ingeniero en Multimedia

Asistente de investigación

Universidad Militar Nueva Granada, Bogotá, Colombia

Correo electrónico: u1201150@ unimilitar.edu.co

() orcid.org/0000-0003-0000-6675

Google Scholar

\section{Carlos Alberto Rocha}

Castaño

Mg. en Dirección de Marketing

Profesor Universidad Militar Nueva

Granada, Bogotá, Colombia

Correo electrónico: carlos.rocha@ unimilitar.edu.co

๑ orcid.org/0000-0002-2800-5132

Google Scholar

\section{Wilman Helioth Sánchez}

Rodríguez

Mg. en Educación

Profesor Universidad Militar Nueva

Granada, Bogotá, Colombia

Correo electrónico: wilman.

sanchez@unimilitar.edu.co

๑ orcid.org/0000-0001-8007-1877

Google Scholar

\section{Recibido: enero 20 de 2018} Aprobado: mayo 15 de 2019

Palabras clave:

Funciones de relación, ilustración-comunicación, relación texto-imagen, relaciones dialógicas, vías ilustrativas.

Revista KEPES Año 16 No. 20 julio-diciembre 2019, págs. 283-343 ISSN: 1794-7111(Impreso) ISSN: 2462-8115 (En línea) DOI: 10.17151/kepes.2019.16.20.12 


\section{Text-image relationships sorting and visualization model}

\begin{abstract}
The big volume of data and information generated today, has forced the use of different means to achieve better communication. The most commonly used are text and image, which are related by their ecphrasis, which is the verbal representation of a visual representation. Therefore, this article is made in order to identify text/image relationships (TRI), and proposes a classification and visualization model based on the principle of similarity in nature, in order to avoid the proliferation of isolated or independent RTIs. This is achieved through a review and characterization of sources that allow an analysis to be made of the different RTIs, which are processed using documentary techniques and information analysis, allowing a clarification and a differentiated use. In the article, different RTI are based on reality, the message, logical semantics and relevance in comics; likewise, it evidences RTI functions, its different dialogical relationships and ends with illustrative ways. Finally, presents the 2D and $3 \mathrm{D}$ classification and representation models allow to identify classes, hierarchies and spatial location of the RTI structure. Such classification and representation models are key to the objective interpretation and organization of RTI and texts, not only by the reader, but also by computer systems for the extraction of characteristics in context.
\end{abstract}

Key words:

Dialogic relations, functions of relations, illustrationcommunication, illustrative pathways, text-image relations. 


\section{Introducción}

La inclusión de imágenes para acompañar, representar, iluminar o contextualizar textos, ha sido utilizada desde la Edad Media europea con la aparición del libro iluminado, enriqueciendo diferentes periodos de la humanidad, y todos los aspectos de nuestro desarrollo como ser social, influenciando áreas como publicidad, política, educación y ciencia. Así nace el concepto de ilustración:

Una representación visual de un texto o concepto mediante el uso de elementos formales de diseño, técnicas artísticas, simbolismos, abstracciones y estilos gráficos variados, que favorecen la transmisión de información entre emisor (ilustrador) y receptor (observador), la cual puede ser comprendida en diferentes rangos de tiempo, y ser entregada de manera inmediata o secuencial, dependiendo de la naturaleza de la obra. (Menza, Sierra \& Sánchez, 2016, p. 278)

El éxito de las ilustraciones recae en la importancia que tiene la yuxtaposición de texto e imagen para entregar información en libros infantiles como en textos científicos y pedagógicos, ya que esta relación permite reforzar conocimientos, contextualizar al lector, y contribuir a la coherencia y creación de significados (Unsworth, 2006; Fang, 1996). Por tanto, el acercamiento entre texto e imagen clarifica el mansaje y lo hace más comprensible al lector.

La lectura de textos no siempre brinda la información necesaria para la adecuada comprensión de un tema, puede aburrir al lector y lograr que desvíe su interés en un medio visualmente más agradable (Armida, 2013). Además, independiente a la riqueza del idioma, hay descripciones que solo se pueden presentar de manera visual.

Existen diferentes posturas de la ilustración, se cuenta con las que expresan mayor contenido literal, aquellas que transforman el sentido literal del texto, las que representan de manera precisa el texto, entre otras, sin embargo, todas cumplen la función de comunicación basada en requerimientos. 
La comunicación es un intercambio de información entre un emisor y un receptor (Watzlawick, 1985). La comunicación ejercida por las ilustraciones es de corte visual, así, el ojo envía información al cerebro para realizar una interpretación, y en este caso, el intercambio de información se convierte en una recurrencia cognitiva, ya que, entre más sabes, más ves, dependiendo del tiempo de visualización de la imagen (Lester, 2014).

Al ahondar en el hecho conexo, tanto texto como imagen están intrínsecamente relacionados. Teresa Durán (2005) expresa que la ilustración puede ser entendida como lenguaje narrativo debido a su capacidad de contar historias de forma argumental y elocuente. Una ilustración permite entregar mensajes visuales que contienen componentes simbólicos y literales, y genera una respuesta emocional por parte del lector, ya que forman una narración, entendida como la unión adecuada de elementos que permiten contar una historia o transmitir una información. La forma de organizar esos elementos se relaciona con el lenguaje narrativo, es decir, el estilo usado para narrar (Sánchez, 2006).

Para Unsworth (2006), uno de los objetivos de búsqueda y descripción de las $\mathrm{RTI}$, es la comprensión de las contribuciones que la unión texto-imagen genera en la construcción del significado de textos compuestos, configurándose el carácter doblemente representacional de la écfrasis, al ser una representación verbal de una representación visual (Pimentel, 2003). Por lo tanto, en este artículo se describen $\mathrm{RTI}$, haciendo un recorrido documental con diferentes autores, que permita su descripción, categorización y visualización formal.

Más allá de la compresión y la construcción de la imagen, el estudio lo motiva la organización, categorización y visualización de las RTI, para establecer modelos que apoyen estudios posteriores de análisis computacional, almacenamiento y recuperación de texto e imagen, así mismo como base teórica para la construcción de tecnologías. 
La primera sección del presente artículo muestra la ilustración y las RTI, basados en la realidad, el mensaje entregado, el estatus, la lógica-semántica y la relevancia en cómics, además, de las relaciones dialógicas, y también, las funciones de RTI, cerrando con las vías ilustrativas; la segunda sección muestra la metodología; la tercera sección muestra resultados y análisis, que presenta el modelo de clasificación y visualización basada en el principio de similitud en su naturaleza con el fin de estandarizar y evitar la proliferación de RTI aisladas o independientes; finalmente, la cuarta sección trata la discusión y conclusiones.

\section{Antecedentes y marco de referencia}

\section{Las relaciones texto-imagen y la ilustración}

Las RTI inician desde el proceso cognitivo involucrado en la lectura de cada palabra. El texto en sí mismo no permite ver la dimensión de lo que describe, y es trabajo del lector proyectar imágenes mentales para entender cada referente. Domas y Marsh (2003) ayudan a comprender la importancia de las RTI:

Los documentos son herramientas complejas creadas para comunicar mensajes a los lectores. Dentro de los elementos usados en el desarrollo de documentos están la prosa, las imágenes, las fuentes, los tipos, los colores y las relaciones espaciales. El mensaje es un matrimonio de estos componentes, y su interacción es una preocupación crítica para las personas que necesitan transmitir la información de manera efectiva. (Domas \& Marsh, 2003/traducido, p. 647)

Así mismo, Durán (2005) sostiene que en un trabajo de ilustración son más evidentes las características del objeto o situación representada, de esta forma permite hacer distinciones claras y la información se transmite de manera concreta. Durán (2005) afirma que "La relación entre significado y significante es mucho más evidente en la ilustración y, por ende, mucho más impactante y persuasiva" (p. 243). 
Domas y Marsh (2003) afirman que "La función de una ilustración está definida como la relación funcional de una imagen a una cadena de texto" (traducido, p. 648). Debe ser tan contundente, que permita iluminar, comunicar y transmitir (Sung, 2013).

Aunque existen diferencias entre comunicación visual, verbal o escrita, en cuanto al tipo de símbolos que se utilizan y los medios visuales que se emplean para expresar los mensajes, la esencia y relación semántica de la comunicación usada en ambos casos es la misma, y tanto texto como imagen deben ser entendidos como un conjunto intrínsecamente relacionado, y no pueden ser diferenciados pues en las dos vías se genera narración, desarrollan argumentos o significan ideas abstractas (Mitchell, 2009).

La relación entre la comunicación visual y escrita se genera principalmente y por definición en un proceso de ilustración. Combina armónicamente la narración literaria y visual, compartiendo características como la originalidad y voluntad artística, es decir, la creatividad y la decisión de realizarla; la desviación y lo connotativo, entendidos como la idea e imagen mental que generan, y el mensaje no superficial que entregan; la intención comunicativa, función estética y poética, que se refieren a la capacidad de entregar mensajes, orden y apariencia de los elementos de la imagen; las emociones que generan en el receptor, y finalmente la facultad de contar historias, transmitir información y generar conocimiento, características que se relacionan con la ilustración (Sung, 2013). Para ahondar en la coexistencia de texto e imagen, a continuación, se describen algunas relaciones. 


\section{RTI basadas en la realidad}

La representación de la realidad es una de las principales cualidades de las imágenes. La comunicación visual que generan las ilustraciones logra mezclar conceptos de realidad e ilusión, pues la realidad es juzgada por el aspecto de las cosas y no por lo que son. En ese orden de ideas, hay ilustraciones cuyo valor representativo y calidad artística es tan alta que sugieren que el realismo es solo un estilo de representación, fundamentado en el objetivo, comunicar, pero varía según el contenido textual (Mitchell, 2009).

La influencia de lo real sobre el aspecto formal de las imágenes es un tema importante en el estudio de la imagen que ha sido tenido en cuenta por varios autores, entre los que resaltan Jaques Aumont (1992) en su texto sobre la imagen, y Abraham Moles (1976), en su teoría de la información y percepción estética. En ambos casos se puede encontrar que el nivel de representatividad de las imágenes permite identificar símbolos o hechos concretos y en ocasiones relatos, y si estos valores de representatividad son trasladados al plano del documento ilustrado, es posible hablar de una primera forma de RTI.

Valores de la imagen basados en la representación de la realidad

Jacques Aumont (1992), siguiendo a Rudolf Arnheim y la tricotomía propuesta entre la imagen y lo real, permite hacer un paralelo a partir de esta correspondencia y contextualizar esta clasificación en el marco de la ilustración y su nivel de representatividad con el texto, categorizándolo entre las RTI (figura 01). 


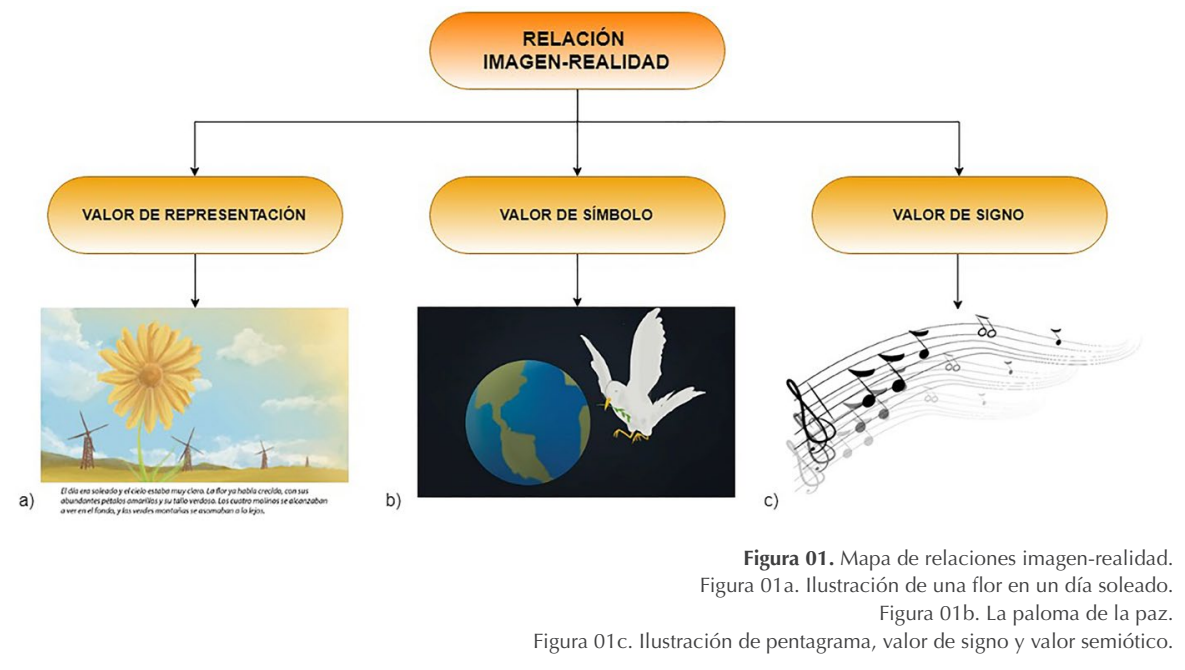

Valor de representación: la imagen es netamente representativa, y procura generar una noción de realismo alto, con la mínima intención de abstracción (Aumont, 1992), por tanto, entre más precisa y objetiva sea la RTI, más representativa será (figura 01 a).

Valor de símbolo: las imágenes tienen un nivel de abstracción alto y se basan en el pragmatismo de los símbolos utilizados, asegurándose de que sean símbolos socialmente aceptados (Aumont, 1992). Las ilustraciones en esta categoría se caracterizan por entregar la información de una manera poco superficial, con el uso de simbolismos y metáforas.

Para comprender la ilustración que demuestra el valor de símbolo (figura 01b), se debe conocer como mínimo, qué se le atribuye a la paloma blanca o al ramo en el pico, ya que son símbolos socialmente aceptados y necesarios para la adecuada interpretación. 
Valor de signo: las imágenes representan la información de manera codificada en conceptos abstractos (figura 01c) que no representan directamente ningún referente de la realidad. Las imágenes se convierten en signo, y "su significante visual no mantiene con su significado sino una relación totalmente arbitraria" (Aumont, 1992).

Nivel de representatividad de las imágenes

Abraham Moles explica que las imágenes entregan mucha información, y pueden tener un mensaje morfológico netamente perceptivo, y un mensaje semiótico, que está ligado a la combinación de signos (Piñuel, 1999) (figura 02).

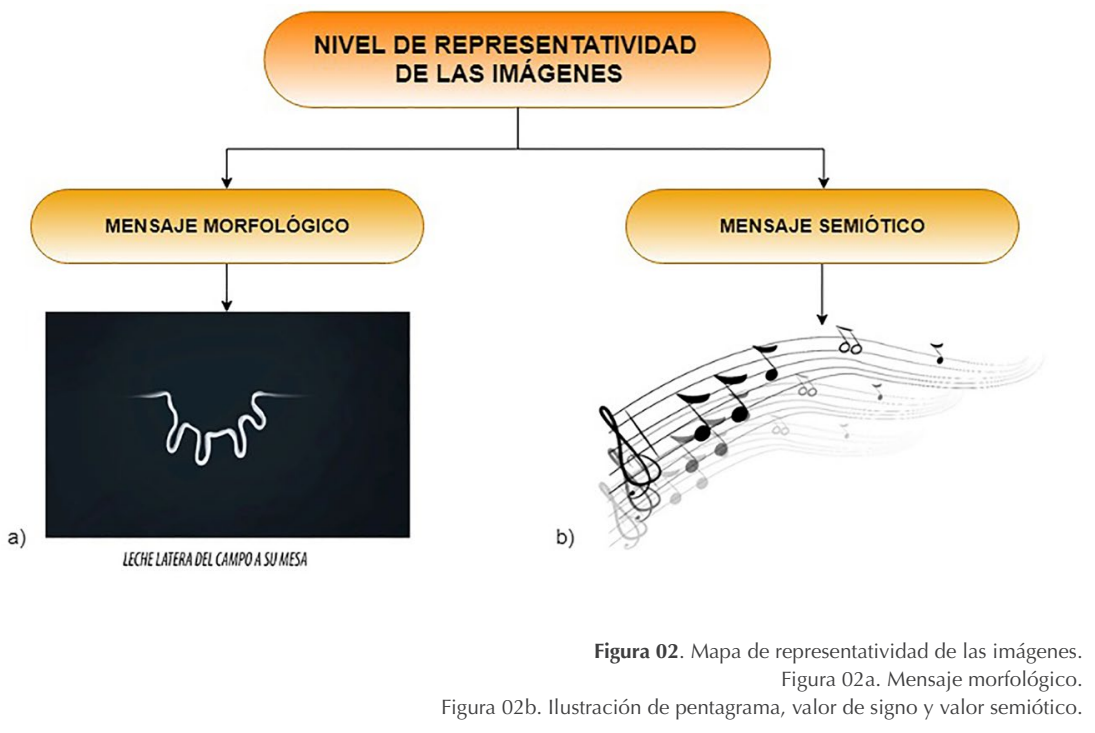


Mensaje morfológico: es entregado por la forma de la imagen, y su relación con el mensaje a entregar (figura 02a), de ahí la importancia de su percepción.

Por el otro lado, se encuentra el mensaje semiótico (figura 02b), cuya relación con el texto se basa en el ensamble de signos, y la representatividad del texto en la imagen es nula. Se relaciona con el valor de signo (Piñuel, 1999).

Moles relaciona estos dos polos mediante un esquema que clasifica imágenes por su nivel de iconicidad de forma descendiente (tabla 01), o nivel de abstracción de forma ascendente (Piñuel, 1999), dándole un nivel de iconicidad máximo de 12 a la imagen netamente representativa con la realidad, y un nivel mínimo de 0 a la descripción en palabras o fórmulas algebraicas (Pacheco, 2009). En esta escala de iconicidad, las ilustraciones pueden encontrarse entre el nivel 6 y 10.

Tabla 01. Escala de iconicidad de Moles.

\begin{tabular}{ll}
\hline 12 & El referente físico real \\
\hline 11 & Modelo bi o tridimensional a escala \\
\hline 10 & Esquema bi o tridimensional reducido o aumentado \\
\hline 8 & Fotografía o proyección realista \\
\hline 7 & Esquema anatómico fotografía de alto contraste \\
\hline 6 & Representación estallada \\
\hline 5 & Esquema de principio \\
\hline 4 & Organigrama o esquema de bloque \\
\hline 3 & Esquema de formulación \\
\hline 2 & Esquema en espacios complejos \\
\hline 0 & Esquema de vectores en espacios puramente abstractos \\
\hline
\end{tabular}

Nota: clasificación de las imágenes por su nivel de iconicidad, cuya escala máxima describe un nivel de representatividad alto, casi real, mientras que el nivel mínimo presenta signos (Moles 1976). 
Las anteriores clasificaciones permiten comprender la importancia de la relación de las imágenes y su nivel de representatividad con lo real, y se puede entender la relación entre esta representatividad y el mensaje entregado, lo que lleva a analizar una segunda forma de clasificación de las RTI.

\section{RTI basadas en el mensaje entregado}

Barthes (1964) analiza las relaciones comunicativas de la imagen basadas en el mensaje lingüístico que generan. El mensaje se compone de elementos lingüísticos organizados como palabras y oraciones, y el discurso es entendido como la emisión de un texto concreto. Estas relaciones se enfocan en el texto o mensaje lingüístico que hay detrás de una imagen.

Las imágenes usan un mensaje lingüístico desde las civilizaciones antiguas, como la egipcia con el libro de los muertos (figura 03a), y se fortalecen a partir de la Edad Media europea con la creación de libros y manuscritos ilustrados (figura 03b). Desde entonces, la ilustración se ha convertido en el principal puente texto-imagen, y el mejor referente para el análisis de RTI.

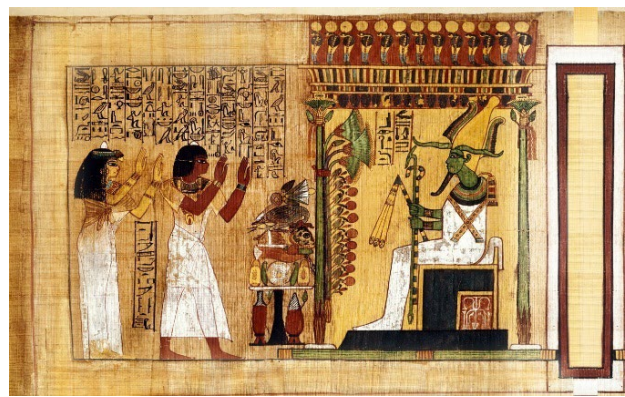

Figura 03a. Libro de los muertos, Rendir cuentas ante Osiris [Pintura mural]. (1900 a.c) Recuperado de: http://www.nationalgeographic.com.es/historia/grande-reportajes/ el-libro-de-los-muertos-6239. National Geographic.

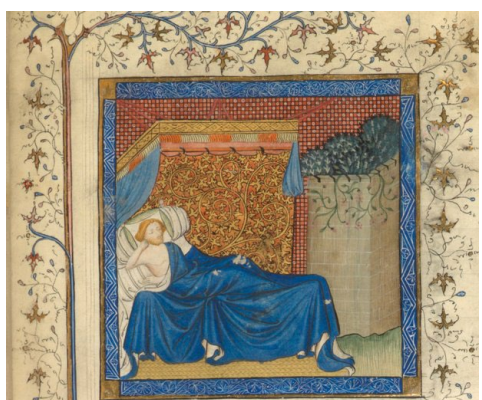

Figura 03b. Manuscritos iluminados de Europa. Roman de la Rose. Recuperado de: http://www.wdl.org/es/item/593/. Biblioteca Digital Mundial.grande-reportajes/el-libro-de-los-muertos-6239. National Geographic. 
Según Barthes (1986), existen RTI de anclaje, relevo e ilustración basados en el mensaje lingüístico entregado (figura 04).

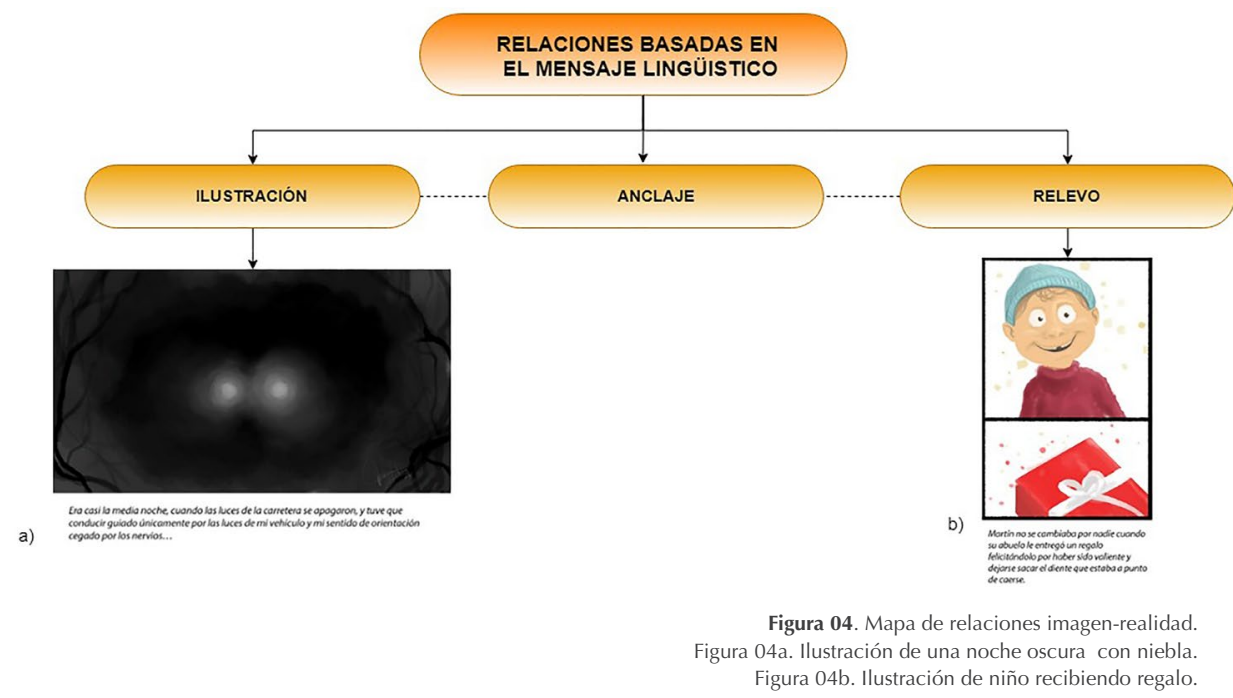

Anclaje: conecta todos los sentidos del objeto mediante una nomenclatura. La lectura de la imagen puede tener múltiples interpretaciones, por eso requiere el uso de un texto que guíe su interpretación por el camino adecuado. Generalmente las imágenes son poco representativas, el texto se utiliza para darle sentido y logra evitar confusiones en su interpretación.

Al ampliar la figura 04a, demuestra que una imagen puede ser interpretada de distintas formas, pero acompañarla con una leyenda o texto puede ser suficiente para contextualizar al lector. 


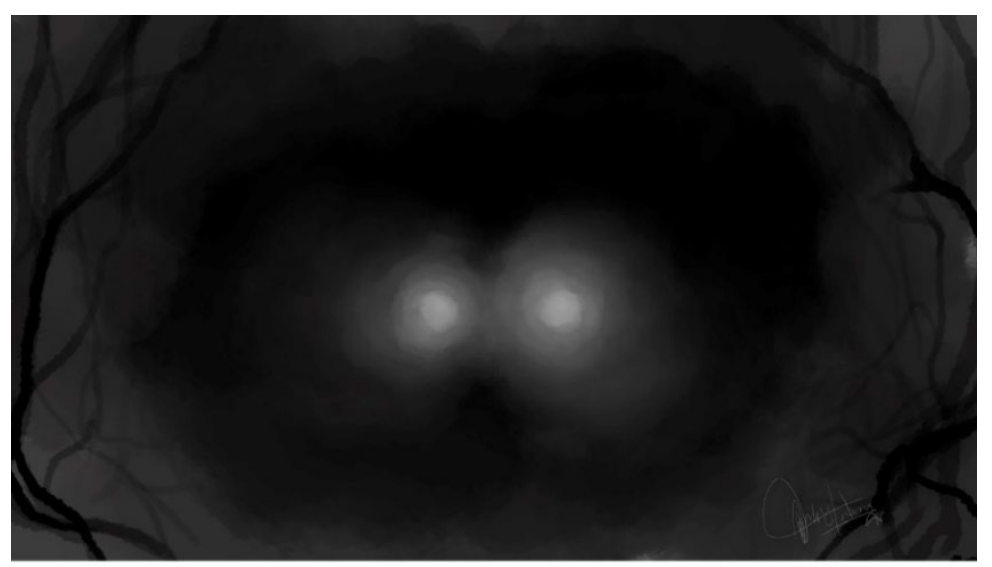

Era casi la media noche, cuando las luces de la carretera se apagaron, y tuve que conducir guiado únicamente por las luces de mi vehiculo y mi sentido de orientación cegado por los nervios...

Figura 04a. Ilustración de una noche oscura y con niebla.

Relevo: se genera cuando texto e imagen se complementan, y el mensaje se entrega en forma de historia. Lo que proyecta la imagen no permite comprender la totalidad del mensaje, y necesita fragmentos de texto como diálogos o descripciones para complementarlo. Es característico de historietas, cómics y caricaturas (Barthes, 1986).

Ampliando la figura 04b, se observa a un niño recibiendo un regalo, pero no demuestra claramente un contexto al receptor y puede terminar en una mala interpretación. En este caso, el texto describe la situación y contextualiza al lector. 


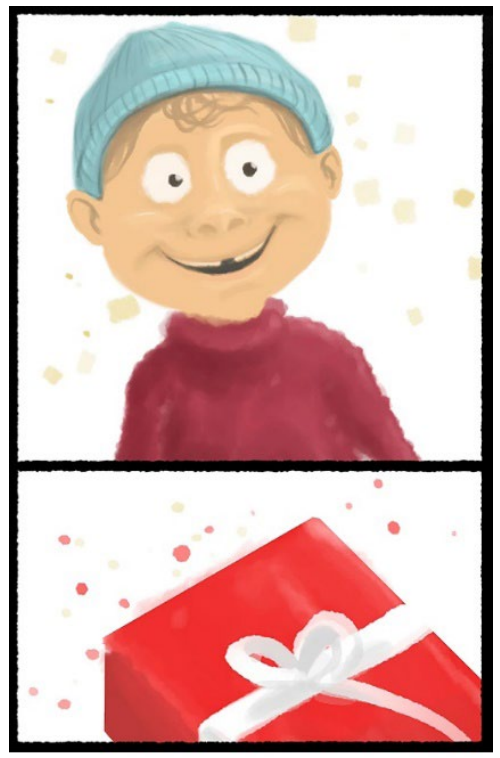

Martín no se cambiaba por nadie cuando su abuelo le entregó un regalo

felicitándolo por haber sido valiente y dejarse sacar el diente que estaba a punto de caerse.

Figura 04b. Ilustración de niño recibiendo regalo.

Ilustración: Chiuminatto (2011) agrega que Barthes acompaña las relaciones anteriores con la ilustración como RTI. La ilustración es una representación visual de textos enfocada a la comunicación de información, desarrollada mediante el adecuado uso del dibujo, el diseño y el manejo de técnicas artísticas (Menza et al., 2016). En esta categoría, la imagen aclara el texto, y por su naturaleza, puede contener cualquier RTI según el contexto utilizado.

\section{Relaciones de estatus}


Martinec y Salway (2011) Ilevan las relaciones generadas entre frases, expuestas por Michael Halliday, al ámbito de las RTI. Comparan dos de ellas desde una perspectiva de estatus y otra lógico-semántica. Según ellos, es posible darle un estatus de igualdad o desigualdad a la relación entablada por texto e imagen (figura 05), y se complementan con la relación de relevo establecida por Barthes (1986).

a)

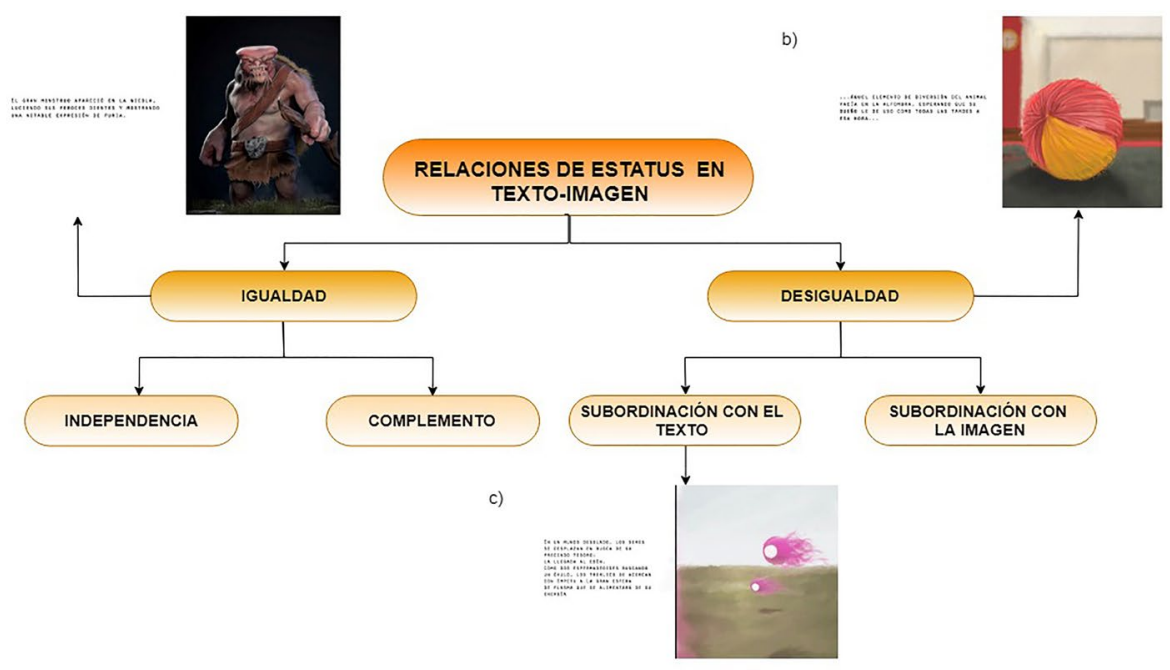

Figura 05. Jerarquía de las relaciones de estatus. Figura 05a. Relación de igualdad-independencia. Figura 05b. Relación de desigualdad-dependencia. Figura 05c. Relación de subordinación con texto.

Igualdad: se genera cuando la imagen y el texto conservan una relación de 
independencia, y cada una puede valerse por sí misma (figura 05a).

El gRan mONSTRUO apareció En La niebla, LUCIENDO SUS FEROCES DIENTES Y MOSTRANDO UNA NOTABLE EXPRESIÓN DE FURIA.

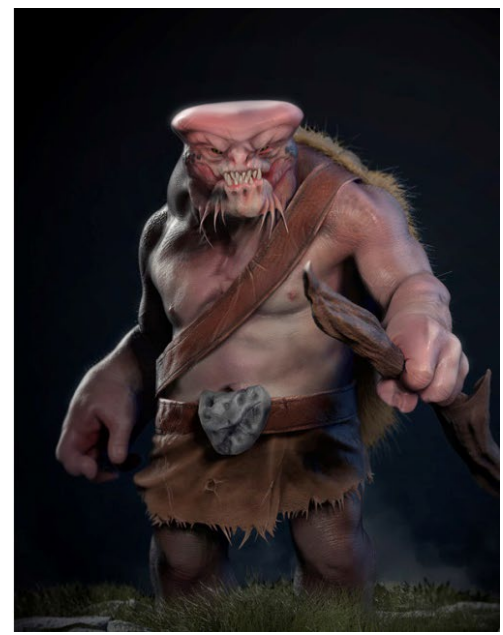

Figura 05a. Relación de igualdad-independencia.

Complemento: Martinec y Salway (2011) añadieron la relación de complemento al estatus de igualdad: tanto texto como imagen están en una sola unidad, y hacen parte de un sistema mayor. El texto está implícito en la imagen, no necesariamente debe ser visible, pero indudablemente debe estar para comprender la imagen.

Cuando las dos relaciones de este estatus (independencia y complemento) se combinan, la totalidad de una imagen representa la totalidad de un texto (párrafo), de lo contrario, si solo una parte del texto (frase o palabra) rige a la imagen, se generan relaciones de subordinación.

Desigualdad: se genera cuando las dos unidades son dependientes (figura 5b), 
y el significado de una, limita la interpretación o cambia totalmente el sentido de la otra.

... Aquel elemento de diversión del animal YACIA EN LA ALFOMBRA, ESPERANDO QUE SU DUEÑO LE DE USO COMO TODAS LAS TARDES ESA HORA...

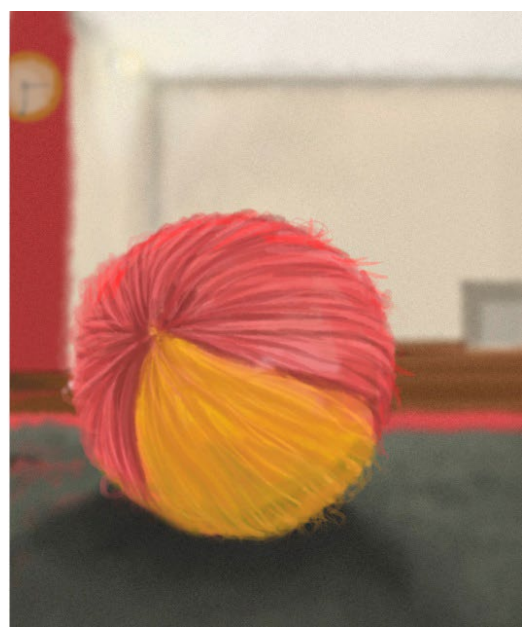

Figura 05b. Relación de desigualdad-dependencia.

Subordinación: se genera cuando una parte del texto limita fuertemente una imagen, o cuando una imagen limita una parte del texto, como el comentario de un crítico de arte sobre una obra.

En la figura 5c se observa como la imagen está subordinada por el texto, ya que éste limita fuertemente su interpretación. Es así como estos autores resaltan la importancia de las RTI basadas en el mensaje que logran entregar y la forma en la que este mensaje es entregado. 

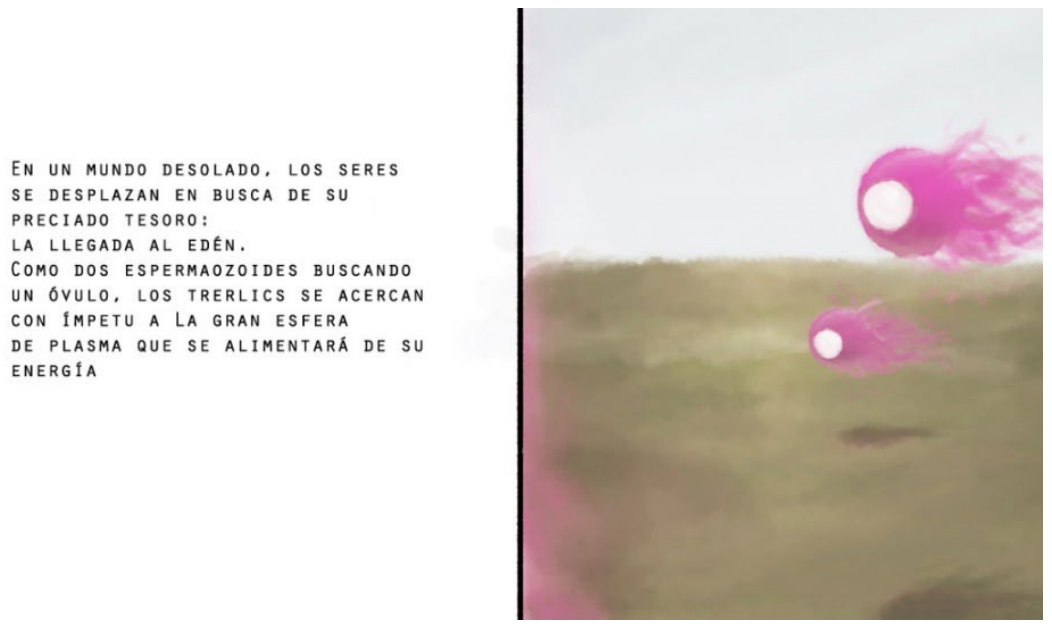

Figura 05c. Relación de subordinación con texto.

Al usar adecuadamente las relaciones anteriores, los autores controlan el mensaje entregado mediante el nivel de detalle o generalidad que presentan en sus textos y las imágenes que los acompañan. De igual forma, es posible comprender correctamente la información, mediante el análisis del conjunto, entendiendo que el aprendizaje no se logra aislando los componentes gráficos y textuales. Así aparece otra clasificación de RTI: las lógico-semánticas.

\section{Relaciones lógico-semánticas}

Martinec y Salway (2011) expresan que las relaciones lógico-semánticas establecidas por texto e imagen (figura 06), se basan en la interpretación del conjunto: teniendo en cuenta la interpretación del significado por su análisis individual, la influencia de cada elemento sobre el otro, y el significado global. 
Menza Vados, A.E. Rocha, C.A. Sánchez, W. / Modelo de clasificación y visualización de relaciones texto-imagen

En este tipo de relación se encuentran dos grandes categorías: expansión y proyección.

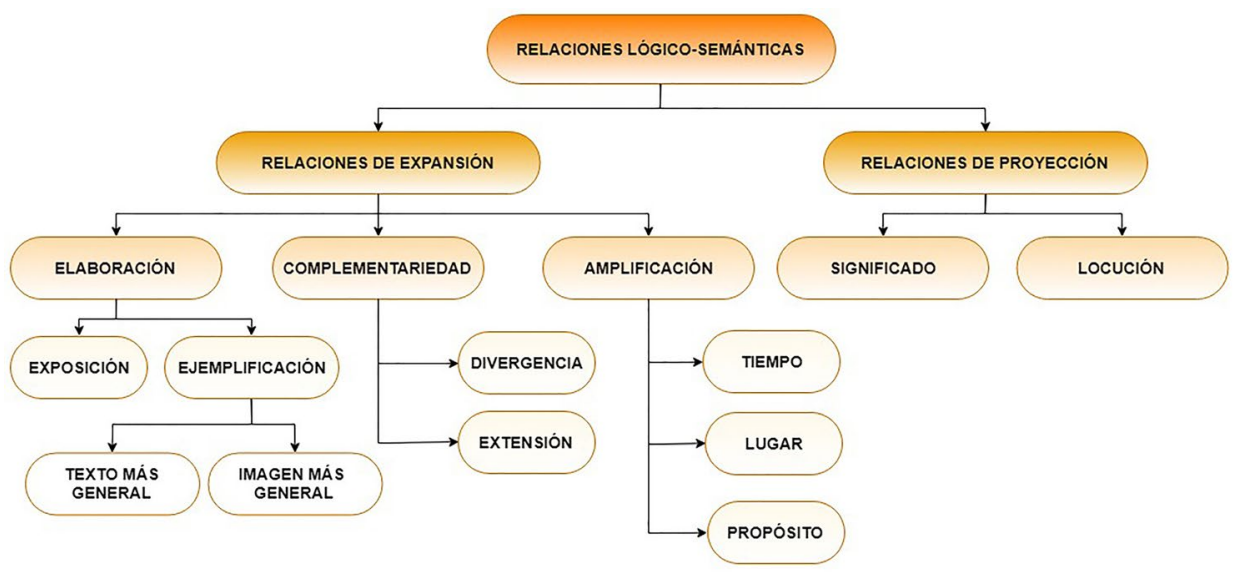

Figura 06. Relaciones lógico semánticas.

Relaciones de expansión

Se basan en la importancia del texto (figura 07). Se da cuando el texto entrega información que pueda complementar, añadir, expandir, limitar, sesgar o ejemplificar elementos de la imagen para fortalecer el mensaje entregado, y obliga a que su interpretación requiera la lectura de ambos elementos (Martinec \& Salway, 2011).

Chiuminatto (2011) explica claramente la relación de expansión expresada por Martinec y Salway (2011). Existen tres categorías: elaboración, extensión y realce o amplificación. 


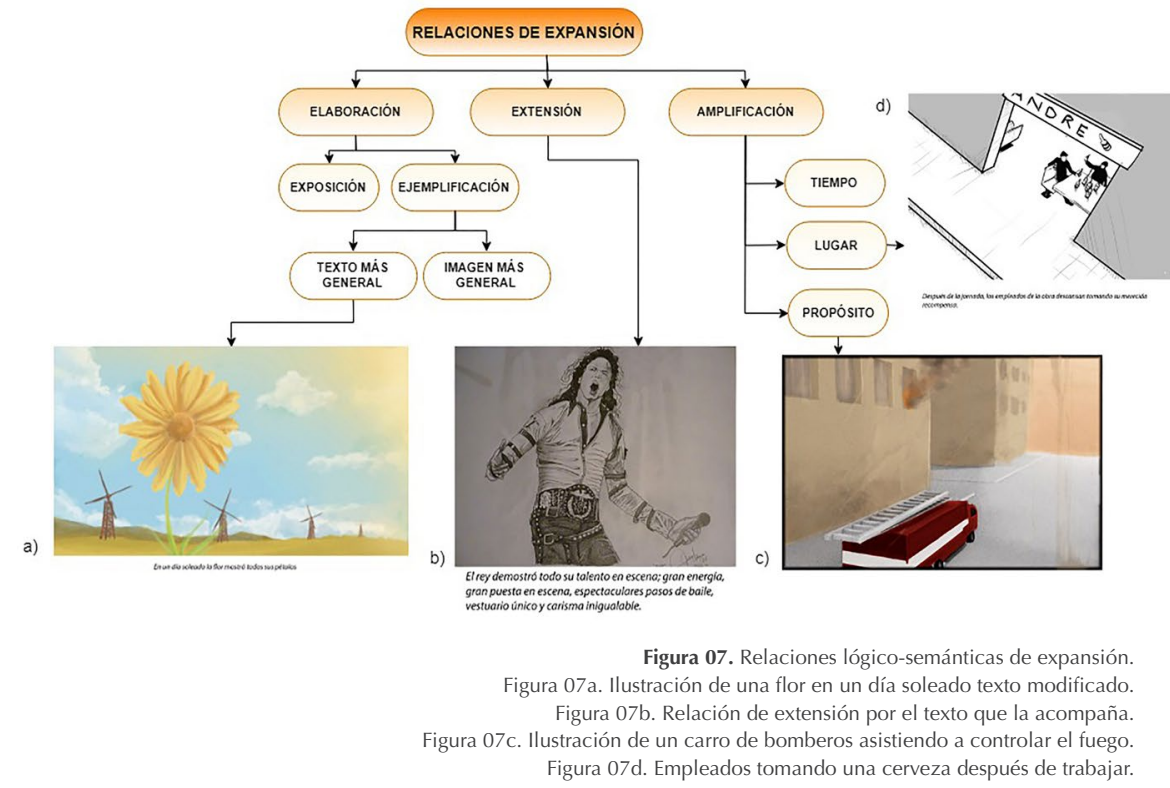

Elaboración: se divide y complementa con ejemplificación y exposición, y se basa en el nivel de generalidad que se puede encontrar en texto e imagen. Cuando una imagen es más general que el texto que la acompaña, o un texto es más general que la imagen, tiene una relación de elaboración con corte de ejemplificación (figura 07a), mientras que, si texto e imagen conservan el mismo nivel de generalidad, la relación que domina es la exposición (Martinec \& Salway, 2011).

Al utilizar la figura 07a con un texto diferente, se observa que una misma ilustración puede tener diferentes significados e interpretaciones de acuerdo al texto que la acompaña o el contexto en el que se presente, por ende, se pueden presentar diferentes RTI. En este caso, como el texto es más general, y 
la imagen entrega mucha más información que el texto que la acompaña, se tiene una relación de ejemplificación.

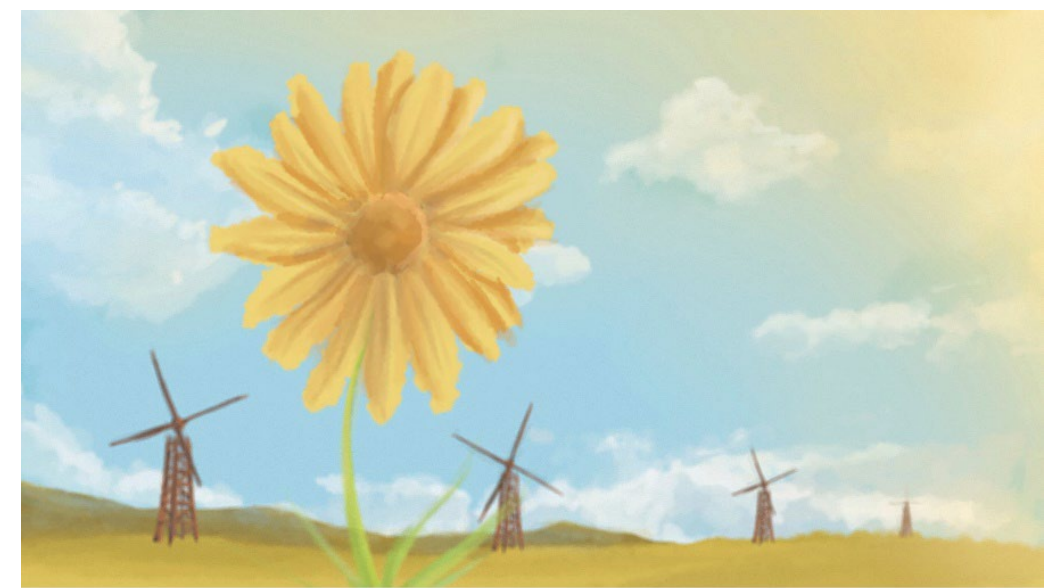

En un día soleado la flor mostró todos sus pétalos

Figura 07a. Ilustración de una flor en un día soleado texto modificado.

Extensión: un medio entrega información adicional y relacionada con lo que expresa el otro (Martinec \& Salway, 2011). Al ampliar la figura 07b, se muestra un ejemplo de dicha relación.

Amplificación: se da cuando uno de los dos, texto o imagen, entrega información adicional o complementaria. Un ejemplo se da cuando en un periódico aparece este mensaje: La catástrofe se generó por un descuido de la madre, quien no se percató de revisar la llave del gas antes de salir. Esta relación califica el uno al otro, considerando tiempo, lugar y razón. 


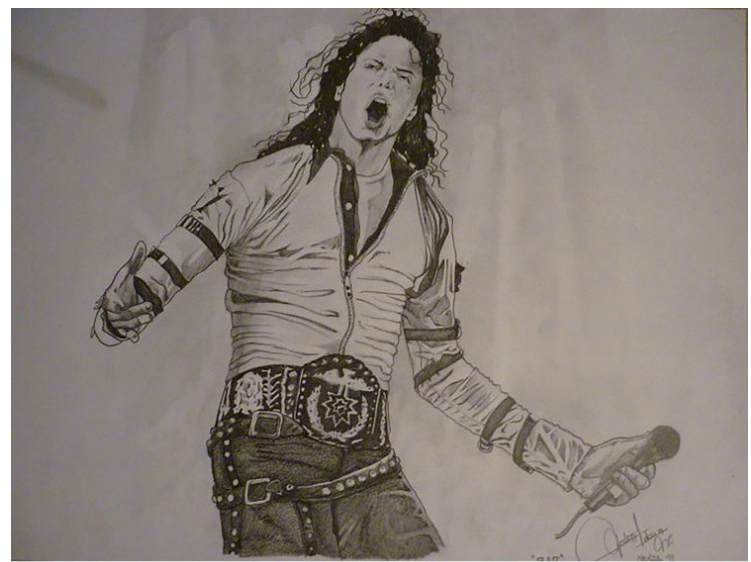

El rey demostró todo su talento en escena; gran energía, gran puesta en escena, espectaculares pasos de baile, vestuario único y carisma inigualable.

Figura 07b. Relación de extensión por el texto que la acompaña.

Por otro lado, la figura $07 \mathrm{c}$, el carro de bomberos indica que ocurrió un incendio y lo intentan controlar, y entre más descriptiva sea la imagen, más conclusiones pueden ser elaboradas. Se genera una relación de amplificación por razón o propósito (Martinec \& Salway, 2011).

Al ampliar la figura $07 \mathrm{~d}$, se muestra a dos personas tomando una cerveza en la tienda de la esquina, la imagen amplifica el texto por lugar, pues ubica al lector en cómo y dónde los trabajadores toman su merecida recompensa. 


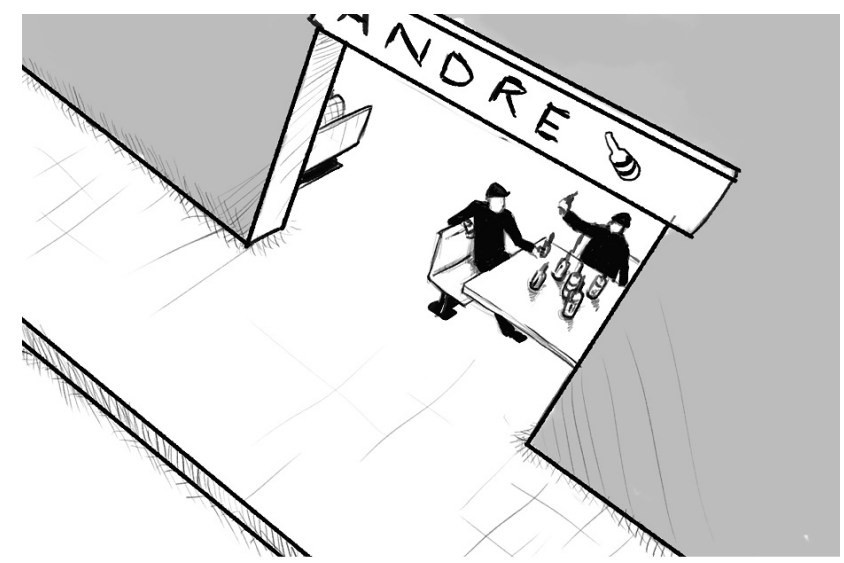

Después de la jornada, los empleados de la obra descansan tomando su merecida recompensa.

Figura 07d. Empleados tomando una cerveza después de trabajar.

Por otro lado, Len Unsworth propone un cambio en el modelo de las relaciones lógico-semánticas establecido por Martinec y Salway, donde la relación de extensión es parte de una categoría más grande conocida como complemento (figura 08).

Complemento: uno de los dos medios dice información diferente pero relacionada con lo que presenta el otro. Dentro de esta relación, además de la extensión, se encuentra la divergencia, importante en la creación de significado en libros ilustrados infantiles, científicos y pedagógicos (Unsworth, 2006).

Divergencia (figura 08a) se genera cuando la imagen y el texto varían en su contenido ideológico (Unsworth, 2006). Es decir, que texto e imagen pueden tener cierta noción de conexión, pero las imágenes no ilustran directamente la acción descrita. Como ejemplo, Unsworth (2006) menciona: 
(...) en los libros de Shirley, de John Burningham (1977; Burningham, 1978) el texto y las imágenes de los padres de Shirley transmiten la narración de una típica visita a la playa o de una niña tomando un baño, mientras que las imágenes de Shirley representan su participación en emocionantes aventuras como sus encuentros con piratas. (Unsworth, 2006/traducido 2016, pp. 1189-1190)

\section{Relaciones de proyección}

Las relaciones lógico-semánticas se complementan con las relaciones de proyección (figura 09), que, contrario a las relaciones de expansión explicadas, se basan en el significado semántico del texto en las imágenes, ya sea por significado o por locución.

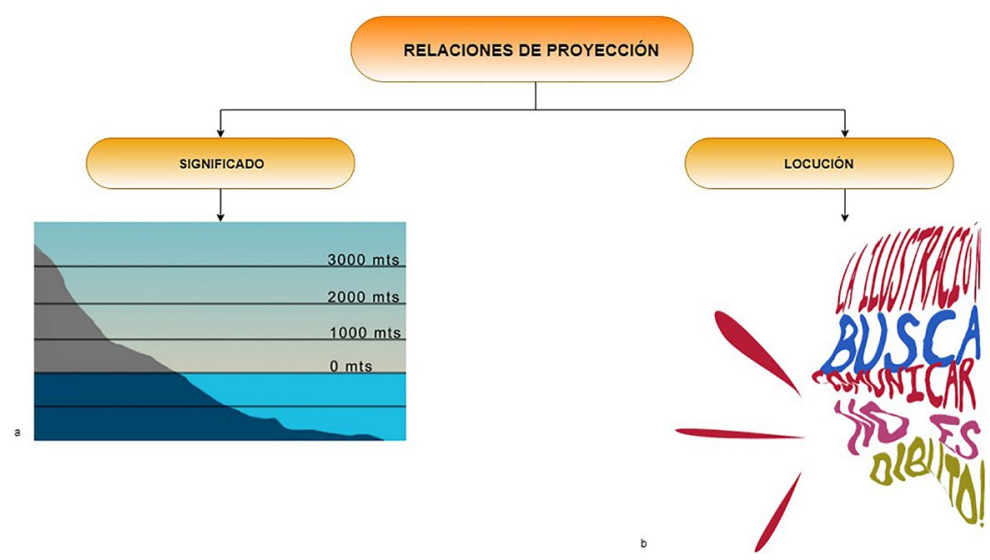

Figura 09. Relaciones de proyección. Figura 09a. Relación de proyección por significado, diagrama de altura de superficie con respecto al nivel del mar. Figura 09b. Relación de proyección por locución. 
Significado: el texto en la imagen representa una idea. Por ejemplo, un diagrama resumen de un texto científico, el cual describe todo el sentido de un texto de manera diferente a como está escrito (figura 09a).

Locución: el texto expresa citas textuales o palabras dentro de una imagen (figura 09b) (Martinec \& Salway, 2011).

Los dos tipos de proyección pueden ser encontrados en historietas, caricaturas o cómics, los cuales, gracias al manejo de símbolos permiten saber si un texto corresponde a un pensamiento, un diálogo o una intervención del narrador.

En las relaciones de proyección y complementariedad se realiza un análisis de los elementos por separado para lograr identificar la relación semántica del conjunto. Por el contrario, en relaciones de elaboración y amplificación, es necesario entender texto-imagen como un todo para lograr obtener el adecuado mensaje.

Adicionalmente se encuentran algunas RTI de dominio específico, como las de relevancia en cómics que a continuación se explican, con el fin de identificar la importancia de la imagen con respecto al texto y viceversa, pensando siempre en la mejor transmisión del mensaje según el contexto en el que se presenta.

\section{Relaciones de relevancia en cómics}

El cómic es arte secuencial, un tipo de ilustración que representa un guion o libreto en una secuencia de imágenes. Scott McCloud (1993) definió el cómic como: "Una yuxtaposición de imágenes y otros elementos gráficos secuencialmente organizados, con el objetivo de entregar una información o producir una respuesta emocional en el lector"; además, en su libro Making Comic identifica que los cómics han evolucionado como una danza entre texto 
e imagen, enfatizando en las bondades y fortalezas individuales y en conjunto, como un todo, encontrando equilibrio perfecto entre los dos (McCloud, 2006).

Por otro lado, Gubern (1987) declara que:

El cómic es un medio de comunicación escrito-icónico (como lo es el cartel) pero estructurado en imágenes consecutivas (viñetas), que representan secuencialmente fases consecutivas de un relato o acción, y en las que se suelen integrar elementos de escritura fonética. En este medio semióticamente mixto, la imagen desempeña una función hegemónica, ya que son posibles los cómics sin palabras, pero no sin dibujos. (p. 217)

Dicho lo anterior, McCloud (1993) identifica y menciona en su libro Understanding Comics, siete relaciones que se pueden establecer entre el texto y la imagen (figura 10). McCloud (1993) las menciona como una serie de combinaciones que pueden clasificarse de la siguiente forma (pp.153-158):

- Palabra-específica.

- Imagen-específica.

- Dúo-específica.

- Combinación aditiva.

- Montaje.

- Combinación paralela.

- Interdependencia. 


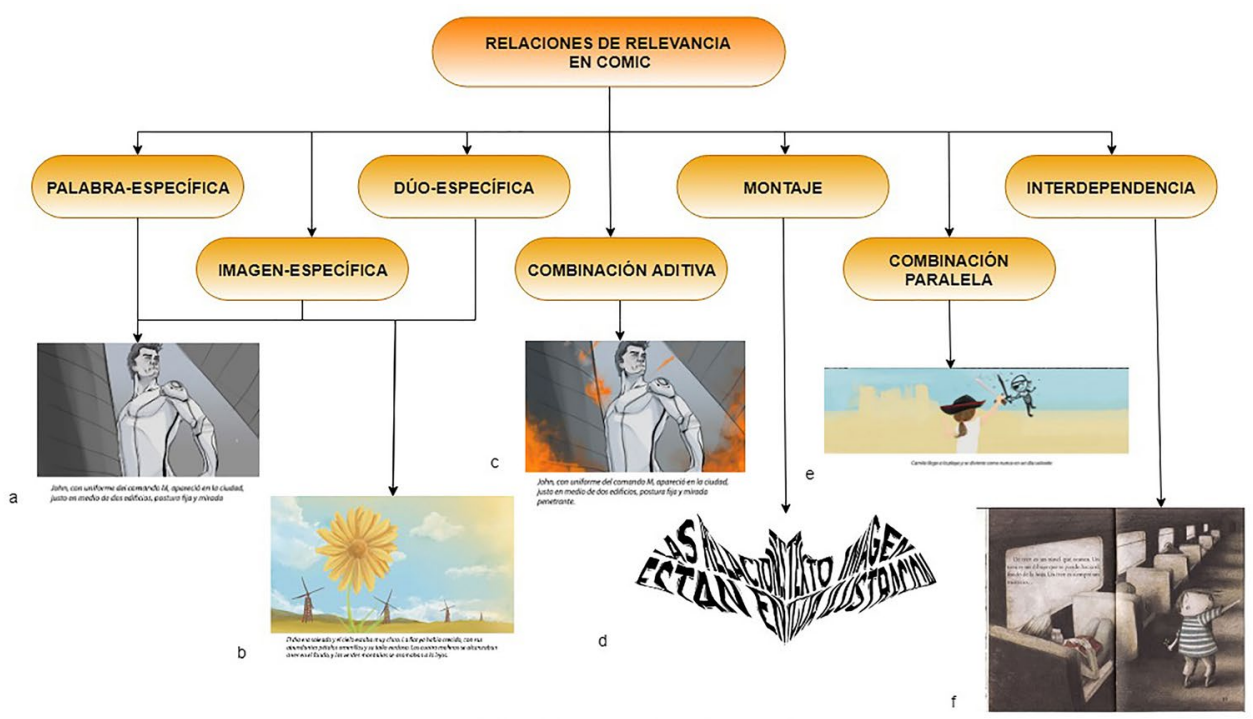

Figura 10. Relaciones de relevancia en cómic. Figura 10a. Viñeta de cómic. Figura 10b. Ilustración de una flor en día soleado. Figura 10c. Ilustración y leyenda-dependencia entre texto e imagen. Figura 10d. Relación de proyección por locución. Figura 10e. Niña jugando en la playa.

Figura 10f. Cuando San Pedro viajó en tren, interdependencia texto e imagen. Recuperado de: https://cubosdemitorre.files.wordpress. com/2010/04/img_00013.jpg

Palabra-específica: la imagen representa el texto, pero no es de gran relevancia en su comprensión, ya que la ilustración no agrega más información a la ya dada por el texto (ampliando figura 10a), en ese caso, el texto podría valerse por sí mismo. En un caso extremo, la imagen visualiza exactamente lo que el texto describe y se genera una relación dúo-específica (McCloud, 1993). 


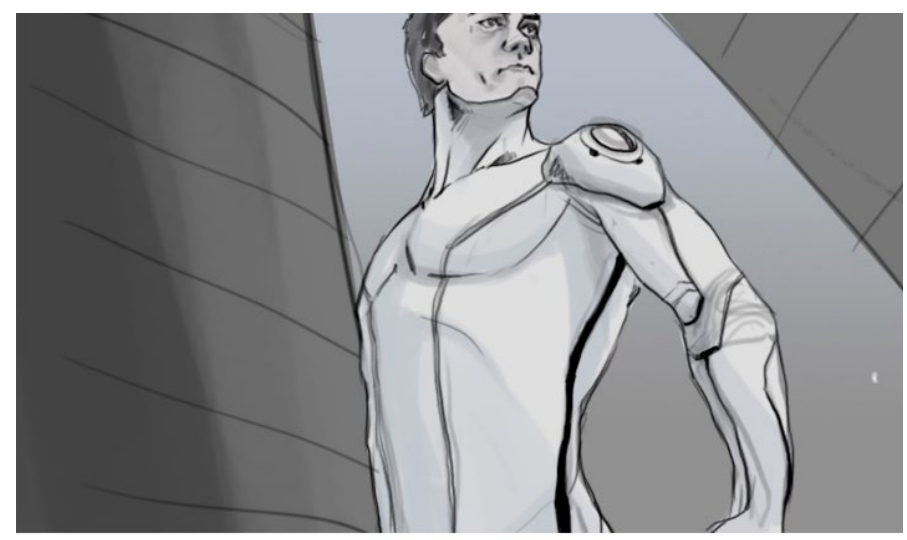

John, con uniforme del comando $M$, apareció en la ciudad, justo en medio de dos edificios, postura fija y mirada

Figura 10a. Viñeta de cómic.

Imagen-específica: contrario a palabra-específica está la imagen-específica, en cuyo caso, la imagen puede llegar a valerse por sí misma. El texto que acompaña las imágenes no entrega información adicional, ni descripción literal más allá de la representada visualmente en la imagen, y su máxima contribución, en cómics, es un sonido a una secuencia de imágenes (McCloud, 1993).

Dúo-específica: se presenta cuando imágenes y texto entregan exactamente el mismo mensaje. En este caso, si la imagen es totalmente representativa con el texto o la leyenda que la acompaña, este último no se requiere (McCloud, 1993). 
Al usar el ejemplo empleado en el valor de representatividad (figura 10b), es posible encontrar las tres relaciones anteriores: el texto es suficientemente descriptivo para requerir una imagen. La imagen es suficientemente representativa para necesitar un texto. Ya que si ambos describen los mismos hechos, no tiene sentido usar los dos juntos.

Combinación aditiva: la imagen o el texto amplifica la información entregada por el otro, así, se genera un complemento de los dos elementos, y el lector puede comprender mejor la información. Usando el mismo ejemplo de la combinación palabra específica, si se hacen algunos cambios a la ilustración ampliando (figura 10c), es posible obtener una amplificación de la información dada por el texto, en este caso, el fuego y los ataques contextualizan la situación y permiten una mayor claridad en su comprensión.

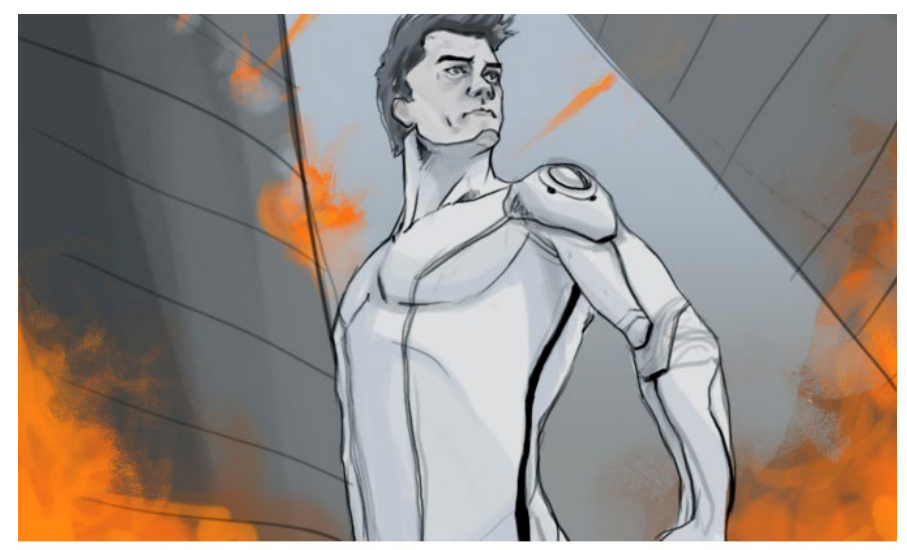

John, con uniforme del comando $M$, apareció en la ciudad, justo en medio de dos edificios, postura fija y mirada penetrante.

Figura 10c. Ilustración y leyenda-dependencia entre texto e imagen. 
Montaje: se asemeja a la relación de proyección por locución, se genera cuando el texto hace parte de la imagen, y es utilizada como recurso en cómics, publicidad y libros narrativos (figura 10d).

Combinación paralela: está relacionada con la divergencia mencionada por Unsworth (2006). Esta establece una independencia, por la cual el texto que acompaña la imagen va por caminos diferentes y paralelos, así, aunque texto e imagen puedan tener una leve conexión (ampliando figura 10e), sus significados no van a converger, y la representación visual no describe de manera directa lo que está escrito.

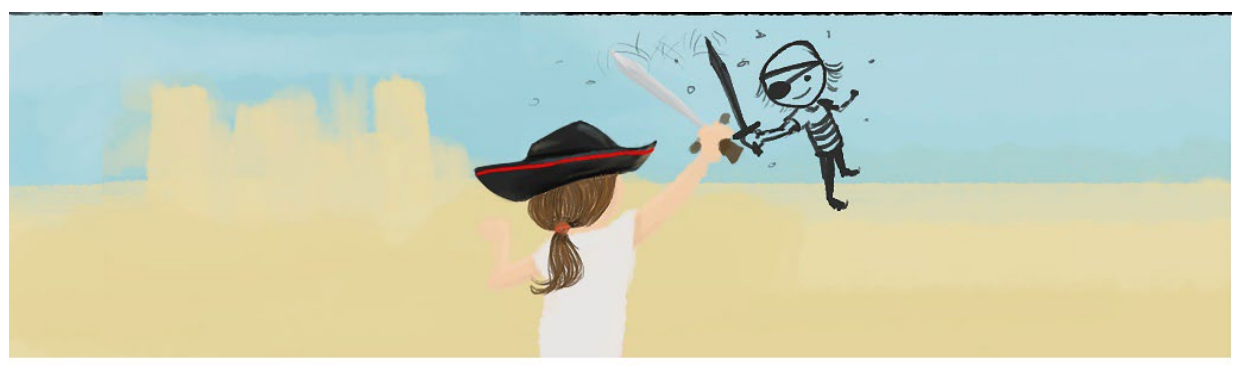

Camila llega a la playa y se divierte como nunca en un día soleado

Figura 10e. Niña jugando en la playa.

- Interdependencia: tanto texto e imagen aportan elementos determinantes para la comprensión de una idea, la cual no podría comprenderse con solo uno de los dos elementos. Pero esta relación no siempre se da de manera equitativa, como McCloud lo dice: "entre más descriptivas sean las palabras, más libertad tendrá la imagen para explorar, y viceversa" (McCloud, 1993/traducido 2015, p.155). 
Al ampliar la figura 10f, es posible ver como la situación que se quiere representar, no puede ser comprendido sin la presencia de los dos medios.

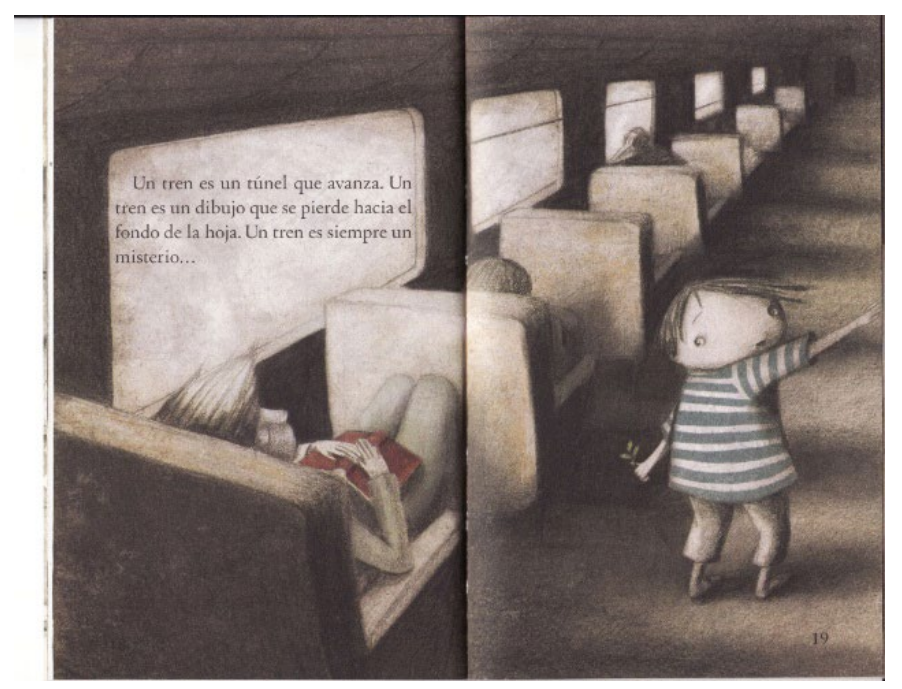

Figura 10f. Cuando San Pedro viajó en tren, interdependencia texto e imagen. Recuperado de: https://cubosdemitorre.files.wordpress.com/2010/04/img_00013.jpg

Adicionalmente, Stein y Thon (2015) mencionan la relación combinación alternante, la cual también tiene relevancia en cómics, y explica las imágenes y las palabras se alternan de manera correcta durante la obra, favoreciendo el adecuado flujo de la narrativa. En las figuras $11 \mathrm{a}-\mathrm{b}$, se muestra que los globos de comentarios ayudan a armar la historia y permiten establecer un contexto más claro. 


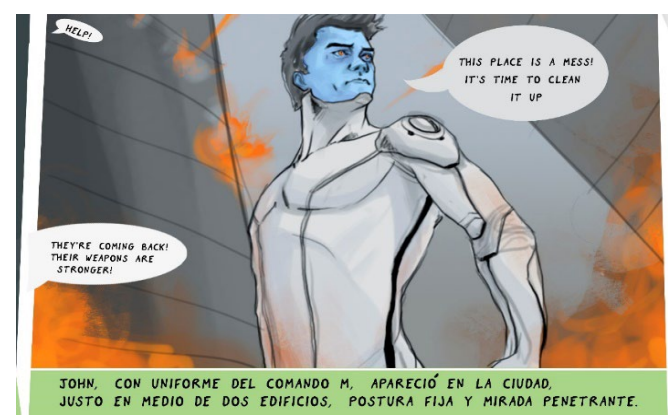

Figura 11a. Relación alternante en cómic.

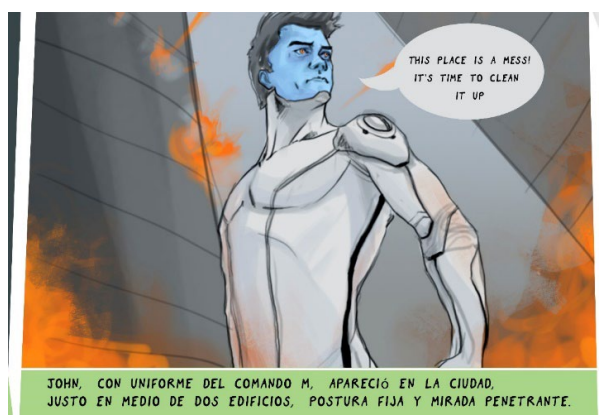

Figura 11b. Viñeta de un cómic.

Las RTI en cómics se basan principalmente en la relevancia de un elemento respecto al otro buscando la mejor transmisión de información. Las relaciones de relevancia en cómics aportan diferentes escenarios posibles, que permiten apoyar múltiples situaciones haciendo énfasis en el texto, la imagen o las diversas relaciones que pueden coexistir a la hora de realizar un cómic. Gracias a ellas es posible la correcta interpretación de las viñetas como ilustraciones independientes, lo cual posibilita la adecuada lectura de la historia completa.

La lectura de imágenes es un campo de preocupación de las diversas áreas del conocimiento, por eso cada vez más autores buscan encontrar la conexión entre ellas y el texto que representan. Al dirigir estas relaciones a la interpretación de ilustraciones, José Rosero (2010) propone un grupo de relaciones específicamente desarrolladas para su apropiada lectura: relaciones dialógicas.

\section{Relaciones dialógicas}

Las relaciones dialógicas propuestas por Rosero (2010) aparecen al estudiar el nivel de significación existente entre el lenguaje visual y escrito presente en el libro álbum, estas relaciones son: vasallaje, clarificación, simbiosis, ficción 
y taxonomía, las cuales se encuentran al mismo nivel, pero con diferente caracterización (figura 12).

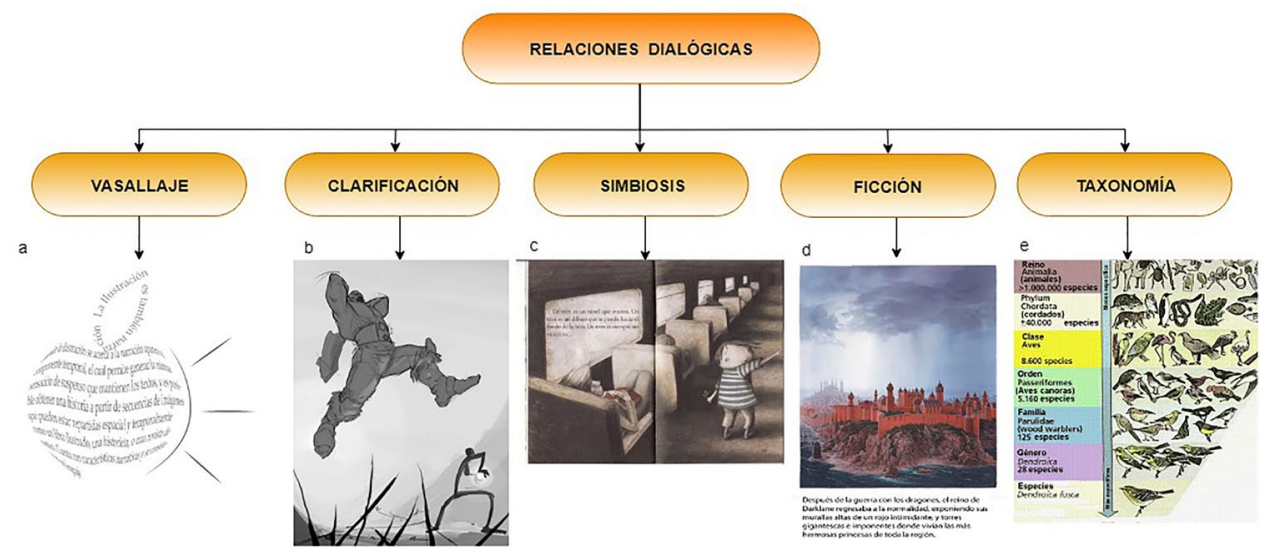

Figura 12. Relaciones dialógicas. Figura 12a. Relación de vasallaje, la cual da una definición de ilustración, obtenida de (Menza, et al. 2016). Figura 12b. Relación de clarificación. El orco ataca al valiente soldado.

Figura 12.c. Cuando San Pedro viajó en tren, interdependencia texto e imagen. Recuperado de: https://cubosdemitorre.files.wordpress. com/2010/04/img_00013.jpg. Figura 12d. Relación de ficción. Texto propio de autores. Recuperado de: http://www.fantasymundo.com/articulos/3801/entrevista_ted_nasmith_pasajes_cast_illos_cancion_hielo_fuego. Figura 12e. Taxonomía de aves. Recuperado de: http://www.biologia.edu.ar/biodiversidad/clasif.htm

Vasallaje: presenta textos que pueden valerse por sí mismos (figura 12a), en cuyo caso, la ilustración no juega un papel mayor a uno descriptivo o decorativo.

Clarificación: la ilustración evoca directa o indirectamente personajes (figura 12b), situaciones o entornos del texto, pero con una interpretación subjetiva del ilustrador, así, su imaginación y simbología permiten crear una imagen que contenga más información que el texto, y así complementarla. Se usa en libros infantiles o textos narrativos, en cuyo caso, la imagen refleja el texto a su manera. Simbiosis: presenta una característica de dependencia, es decir que el texto sin 
imagen, o viceversa, no funcionan y no pueden comprenderse (figura 12c). La imagen contiene información que el texto no incluye, y el texto evoca lo que la imagen no contiene. De esta forma, la simbiosis permite la manipulación del equilibrio, entre texto e imagen en la narración.

Ficción: se presenta con la contextualización de un mundo o situación imaginarios, ampliando la figura $12 \mathrm{~d}$ se ilustra una parte de la novela "Canción de hielo y fuego". Para que el texto sea creíble, es necesario que la imagen demuestre una coherencia gráfica, lo cual evita que el lector piense que el texto es falso.

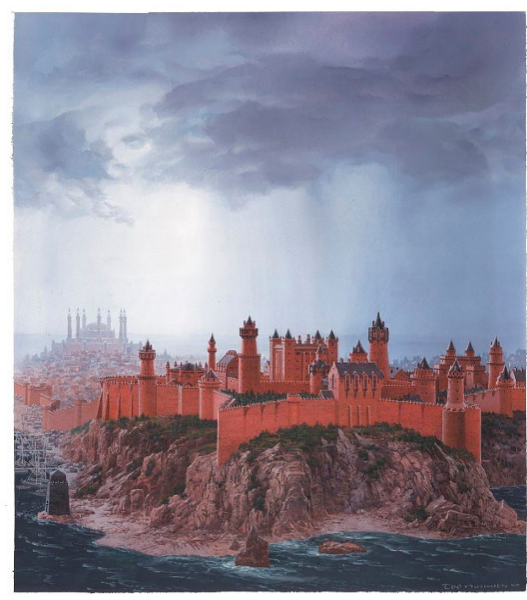

Después de la guerra con los dragones, el reino de Darklane regresaba a la normalidad, exponiendo sus murallas altas de un rojo intimidante, $y$ torres gigantescas e imponentes donde vivían las más hermosas princesas de toda la región.

Figura 12d. Relación de ficción. Texto propio de autores. Recuperado de: http://www.fantasymundo.com/articulos/3801/ entrevista_ted_nasmith_pasajes_cast_illos_cancion_hielo_fuego. 
Taxonomía: los elementos de los textos como historia, personaje o concepto son explicados y clasificados por imágenes que, aunque no tengan una relación narrativa entre ellas, mantienen una congruencia global (figura 12e) y "(...) construyen un relato visual y escrito por medio de la unión de partes que esta descomposición presenta, de manera que el libro se compone de los fragmentos que forman el total" (Rosero, 2010).

Al ampliar la figura 12e, se identifica la temática sin necesidad de que las imágenes se relacionen directamente entre ellas o el texto de manera específica.

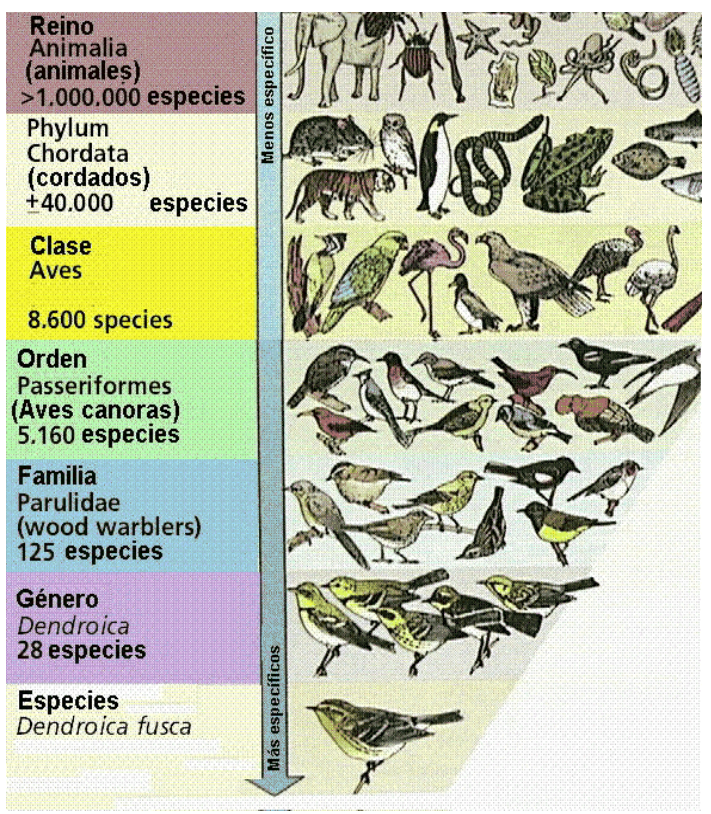

Figura 12e. Taxonomía de aves. Recuperado de: http://www.biologia.edu.ar/biodiversidad/clasif.htm. 
De lo anterior, se establece que tanto la creación como la interpretación adecuada de ilustraciones narrativas debe basarse en el significado del conjunto texto-imagen, tal como sucede con las relaciones de expansión anteriormente descritas. La significación se obtiene gracias a la conexión y diálogo existente entre ambos lenguajes. Pero en ocasiones, las imágenes presentan la intención del autor, y generalmente su postura frente al contexto en el que se exhiben, y debido a esto su interpretación puede ser tan objetiva como subjetiva. Buscando que el diálogo texto-imagen sea equitativo, Domas y Marsh (2003) proponen múltiples relaciones basadas en funciones que permitan generar trazabilidad hacia la búsqueda de la objetividad.

\section{Funciones de las RTI}

En su artículo de taxonomía de las RTI, Marilyn Domas y Emily Marsh (2003) compilan 49 funciones de imágenes sobre los textos divididas en tres grandes grupos (figura 13), basados en las relaciones que generan con el texto. Este trabajo busca dar importancia a las relaciones que involucran una estrecha conexión entre texto e imagen y permitan realizar una trazabilidad hacia la objetividad en su interpretación, por eso se ahonda en aquellas funciones que sugieren mayor relación con el texto.

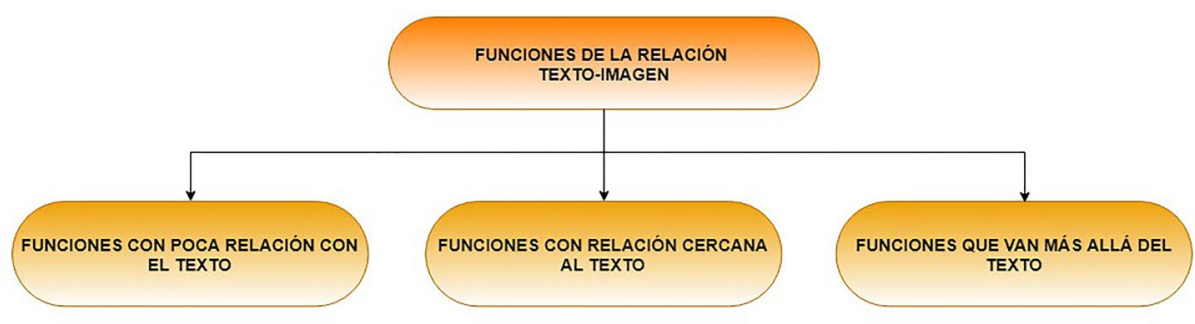

Figura 13. Mapa de las funciones de la relación texto-imagen. 


\section{Funciones de poca relación con el texto}

Un primer grupo menciona las funciones que expresan poca relación con el texto (figura 14), las cuales no buscan influir en la interpretación o significación del texto, pero pueden generar una relación más estrecha con el receptor (Domas \& Marsh, 2003), entre las cuales se encuentran:

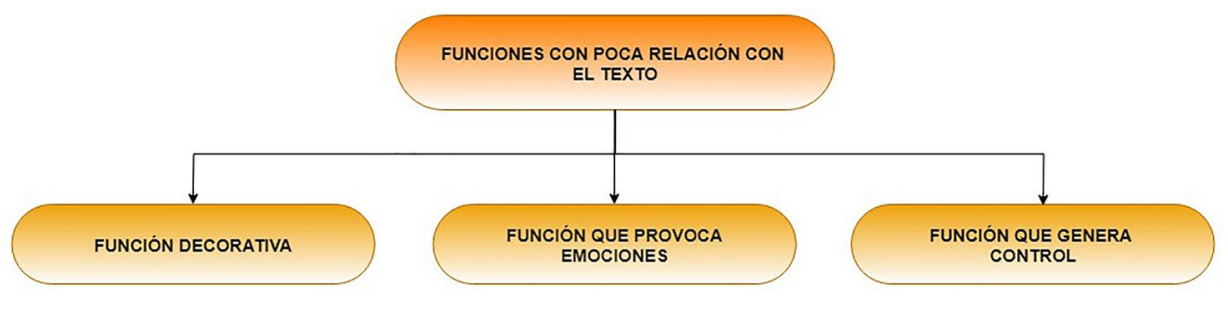

Figura 14. Mapa de funciones que expresan poca relación con el texto.

Funciones decorativas: buscan adornar, ejemplificar un estilo gráfico específico o interrumpir continuidad dentro de un texto, y de esa forma volverlos más llamativos.

Funciones que provocan emociones: tienen un contenido muy explícito que puede ser muy llamativo, desagradable o inquietante, razón por la cual generan automáticamente una respuesta emocional en el lector.

Funciones que generan control: las ilustraciones conducen la interpretación del lector, dirigiendo su atención a partes específicas, pueden retener la atención del usuario o provocar una respuesta en él. 


\section{Funciones de relación cercana con el texto}

La significación del conjunto texto-imagen es posible mediante la adecuada lectura e interpretación de ambos elementos, gracias a que la información contenida en uno puede estar limitada, sesgada o ampliada por el otro. Estas funciones, a diferencia del grupo mencionado, tienen una relación explícita con el texto y aportan más que solo un componente llamativo.

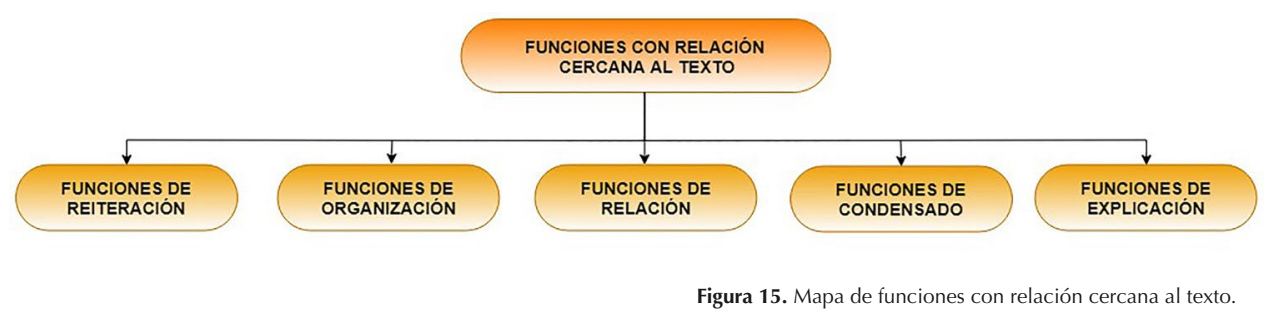

Entre las funciones que expresan una relación cercana con el texto, se pueden encontrar las funciones de reiteración, organización, relación, condensado y explicación (figura 15).

Funciones de reiteración: se presentan cuando la imagen es entendida de manera rápida, sin mayor nivel de interpretación. Puede estar comparada con un nivel de representación alto en las relaciones anteriormente descritas, y su objetivo principal es reafirmar lo que dice el texto. En este caso, las imágenes expresan de manera literal el contenido del texto, y pueden ser calificadas como una "transcripción" o "repetición" (Domas \& Marsh, 2003).

Un objetivo de la función de reiteración es lograr que la información contenida en el texto sea más accesible al lector, es por eso que las ilustraciones tienen un corte descriptivo, y usan recursos como referentes comparativos o representaciones figurativas. 
Las imágenes que presentan reiteración pueden concretar la información descrita en el texto, convirtiendo la relación aún más explícita mediante el uso de leyendas o textos cortos.

Funciones de organización: generan significación del conjunto mediante el uso de imágenes y textos dependientes. Texto e imagen funcionan como una unidad coherente o un todo funcional; crean coherencia, establecen un lugar y un tiempo, comparan elementos de la imagen con el texto, organizan y estructuran un texto (Domas \& Marsh, 2003).

En esta relación, la información se presenta de manera ordenada y estructurada, y tanto texto como imagen son necesarios para su lectura. Algunos ejemplos pueden ser las líneas de tiempo o diagramas (Domas \& Marsh, 2003).

Funciones de relación: las ilustraciones contienen elementos que evocan o se relacionan directamente con conceptos encontrados en el texto, y se valen de comparaciones, contrastes o paralelos. En ocasiones se muestran las mismas acciones que el texto expresa, pero en contextos diferentes (Domas \& Marsh, 2003).

Funciones de condensado: dentro del proceso creativo de un ilustrador, se encuentra una forma de simplificación y separación de textos en palabras clave; siguiendo esta idea, en las funciones de condensado, la imagen se reduce a los elementos básicos o esenciales encontrados en el texto. Se simplifica la información más importante para que el lector la comprenda de manera rápida y efectiva (Domas \& Marsh, 2003).

Uno de los objetivos de las ilustraciones que cumplen esta función, es presentarle al lector la información más relevante, por eso brindan la información del texto de manera concisa y casi resumida. 
Funciones de explicación: las ilustraciones tienen el objetivo de hacer comprensible el texto, para lo cual deben usar elementos que definan lo que el texto propone, o complementen la información brindada para evitar la mala interpretación, es por eso que la relación se presenta únicamente cuando el texto original está seguido de forma cercana a la imagen (Domas \& Marsh, 2003).

\section{Funciones que van más allá del texto}

Cuando las ilustraciones presentan más información que el texto, su interpretación puede tomar mayor tiempo y requerir una mayor contemplación. Según Domas y Marsh (2003), este tipo de relaciones pueden ser clasificadas en funciones de interpretación, desarrollo y transformación (figura 16).

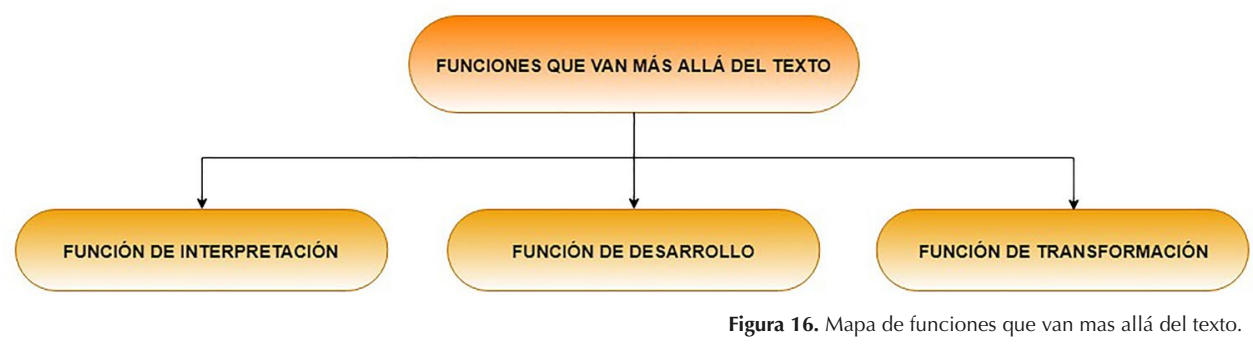

Función de interpretación: se fundamenta en la transmisión e interpretación del mensaje principal, lo cual se puede conseguir haciendo énfasis en la información, volviendo evidente el mensaje, o por la transmisión de esta idea mediante información de soporte y la presentación de argumentos de autoridad (Domas \& Marsh, 2003).

Función de desarrollo: se genera cuando se expone o aclara un texto: la ilustración amplifica con detalles el significado del texto, o viceversa. Un 
medio especifico, provee detalles adicionales o complementa el otro (Domas \& Marsh, 2003).

Esta función se puede comparar con las relaciones de exposición, y se evalúa el nivel de generalidad de un medio respecto al otro. Las ilustraciones de este grupo expanden la información contenida en el texto con datos o detalles específicos, por otra parte, el texto puede ser más específico que la imagen, y puede explicar con mayor claridad una situación.

Función de transformación: se presenta cuando las imágenes relacionan componentes del texto o viceversa. Uno de los dos medios provee información necesaria que el otro no posee para entender el mensaje entregado, de esta forma, entre los dos medios se arma la historia, la cual no podría existir sin imágenes o sin texto (Domas \& Marsh, 2003).

Se genera una simbiosis en la que el contenido total no puede ser comprendido con texto o imagen de manera separada, ya que la historia o contenido de la obra se entrega de manera alternante en ambos medios y la interpretación se basa en la lectura del conjunto.

Al dar una mirada diferente, que complementa y generaliza el trabajo realizado por Domas y Marsh (2003) en cuanto a funciones objetivas, Durán (2005) plantea formas de ver la RTI con una mirada de lo objetivo, subjetivo, afecto e ingenio, lo que denomina vías ilustrativas.

\section{Vías ilustrativas}

Según Durán (2005), es posible establecer otras relaciones entre ilustración y texto basados en la forma en la que el lector recibe la información, y pueden clasificarse en ciertas opciones o vías ilustrativas que generan puentes de 
comunicación entre emisor y receptor. Estas vías son: objetiva, subjetiva, empatía afectiva y empatía ingeniosa (figura 17).

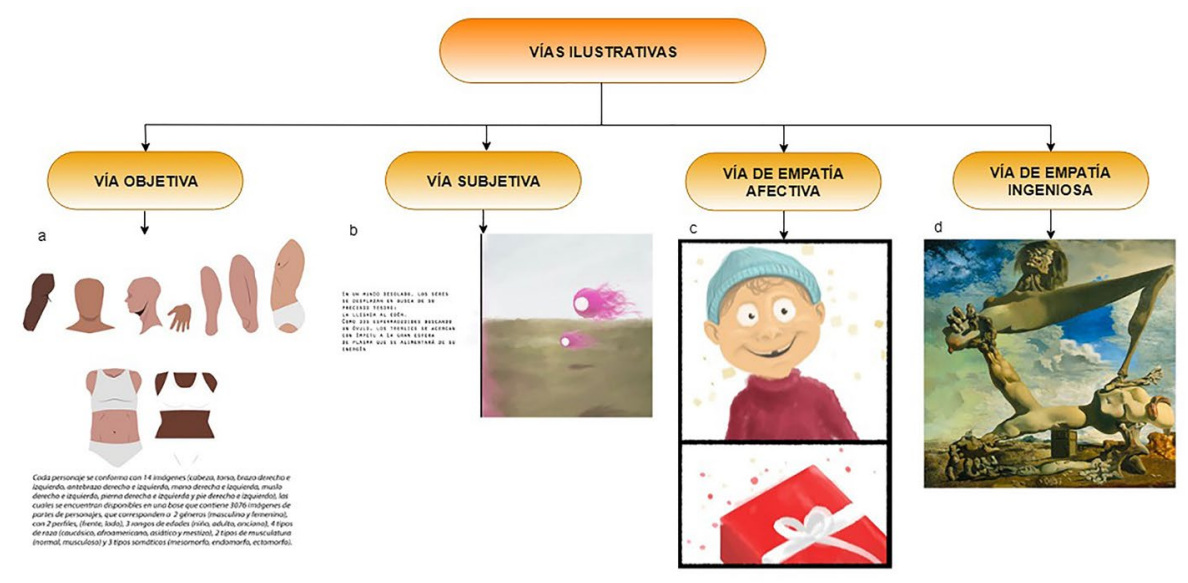

Figura 17. Vías ilustrativas. Figura 17a. Ilustración por partes para construcción de entidad completa. Figura 17b. Relación de subordinación con texto. Contexto de vía subjetiva.

Figura 17c. Ilustración de niño recibiendo regalo.

Figura 17d. Ilustración obtenida por la vía ingeniosa. Recuperado de: http://goo.gl/82UOB2

Vía objetiva: se apega objetivamente al texto y la ilustración representa de manera precisa la información, el ilustrador trabaja como cronista documental. Ampliando la figura 17a se ven algunas partes de personaje de un conjunto de datos, las cuales son descritas por el texto que las acompaña. Las ilustraciones se apegan objetivamente al texto y lo describen plenamente basado en reglas estructurales. 

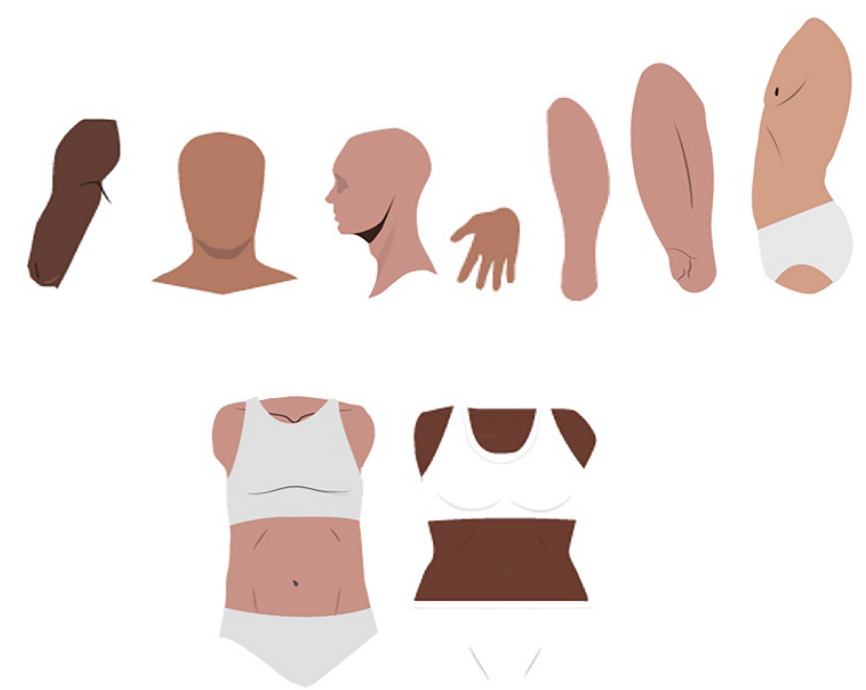

Cada personaje se conforma con 14 imágenes (cabeza, torso, brazo derecho e izquierdo, antebrazo derecho e izquierdo, mano derecha e izquierda, muslo derecho e izquierdo, pierna derecha e izquierda y pie derecho e izquierdo), las cuales se encuentran disponibles en una base que contiene 3076 imágenes de partes de personajes, que corresponden a 2 géneros (masculino y femenino). con 2 perfiles, (frente, lado), 3 rangos de edades (niño, adulto, anciano), 4 tipos de raza (caucásico, afroamericano, asiático y mestizo), 2 tipos de musculatura (normal, musculoso) y 3 tipos somáticos (mesomorfo, endomorfo, ectomorfo).

Figura 17a. Ilustración por partes para construcción de entidad completa

Vía subjetiva: se representa la información leída desde la perspectiva del ilustrador, variando estilos sin cambiar la idea principal.

Al ampliar el ejemplo de subordinación (figura 17b), pueden existir muchas formas de ilustrar ese fragmento de texto, es el ilustrador quien, de acuerdo con su interpretación, estilo y experiencia, decide cómo realizarlo sin perder el sentido de lo escrito. 

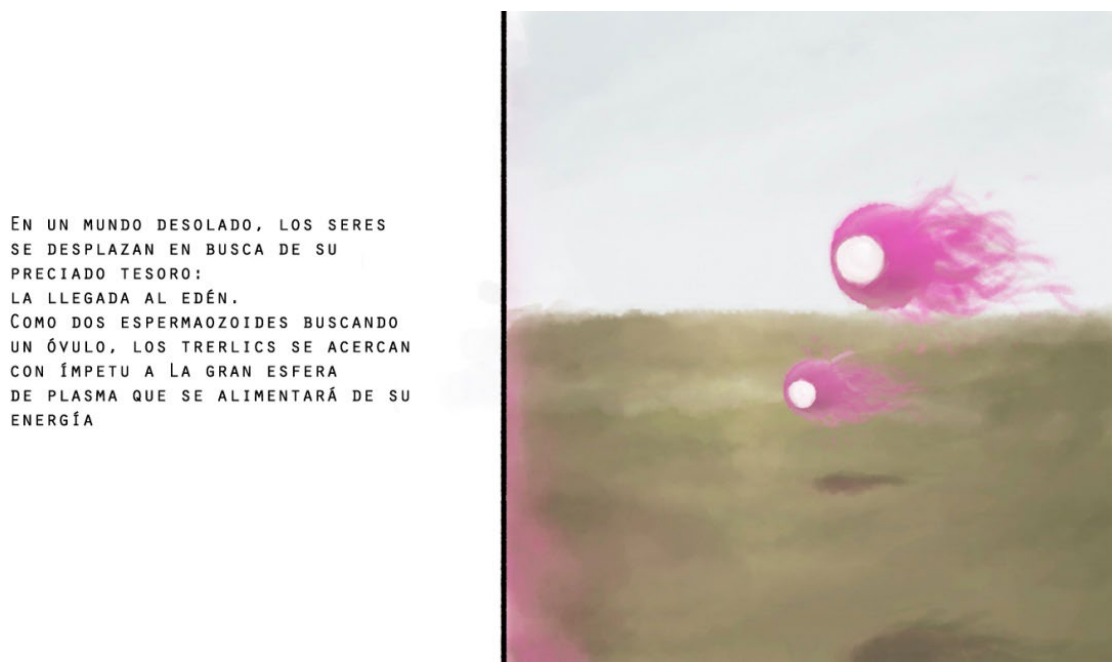

Figura 17b. Relación de subordinación con texto. Contexto de vía subjetiva.

Vía empatía afectiva: resalta el valor poético de la ilustración, busca llamar la atención del lector. Por esta vía, el ilustrador representa los textos, generalmente narrativos, de una manera cariñosa para dirigirse al público objetivo, habitualmente niños. Gracias a la relación que se quiere generar en estos trabajos de ilustración, predominan las formas redondas, los colores pasteles y pieles ruborizadas (figura 17c).

Vía empatía ingeniosa: se caracteriza por el uso de metáforas, simbolismos, y manipulación de fenómenos visuales, obligando al lector a profundizar en la observación de la imagen para entenderla por completo. Es característico que el ilustrador se valga de ilusiones ópticas para lograr establecer la relación (figura 17d). 


\section{Metodología}

Se inició una revisión documental, con elementos propios del análisis de información de las RTI existentes, se procedió a explorar y analizar los enfoques y contextos de las RTI para identificar y generar los extractos, notas y categorías que facilitan el estudio de la información contenida en los documentos. Dicho análisis permitió identificar similitudes en definición, nexos y relaciones.

Seguidamente al análisis, se realizó la síntesis, en la cual se efectuaron cruces de información de las RTI que permitieron identificar categorías. En este proceso se encontró que, incluso dentro de una misma categoría, existe dispersión y concentración de RTI, por lo cual se usaron grupos y subgrupos en la clasificación. Así nacieron los grupos por naturaleza y sus respectivos subgrupos, identificados de manera alfabética para una fácil identificación.

Dentro de las categorías encontradas, existen algunas que pertenecen a contextos diferentes a las RTI, sin embargo, por su significado y relevancia, permiten aportar a la clasificación, mejor comprensión y exaltar su importancia en el lenguaje. Por ejemplo, los niveles de iconicidad de Moles permiten identificar la similitud de una forma, con aquello que representa. Esta escala de iconicidad es estudiada en un contexto de forma-lenguaje, y en este artículo, se trasladó a un contexto texto-imagen, en el que esta escala de iconicidad permite identificar la similitud de la imagen con el texto que representa.

Los niveles de iconicidad de la imagen propuestos por Moles, trasladados al objeto de estudio, también permiten clasificar los grupos de RTI previamente creados. El objetivo de esta nueva clasificación es validar el nivel de representatividad de las imágenes con respecto al texto. En donde el máximo nivel de representatividad se relaciona con una imagen que expresa de manera literal y precisa la información escrita, y el mínimo nivel evoca la máxima abstracción de la imagen respecto al texto que representa. 
En este punto, se identificó que al trasladar los niveles de iconicidad al contexto de texto-imagen, es posible unificar pares de niveles de iconicidad de acuerdo con la escala. Por ejemplo, los niveles 6, representación estallada, y 7, esquema anatómico, permiten simplificar y describir productos. Aunque en el contexto planteado por Moles tienen funciones diferentes, en el ámbito de su relación con el texto, pueden converger, y se relacionan con las RTI en las que, el objetivo de la imagen es describir lo que el texto propone. De esta forma nació la propuesta de clasificación basada en Moles Ilamada intervalos de representación.

Adicionalmente, al ahondar en la investigación se identificaron categorías que envuelven, o califican las relaciones presentes entre palabra e imagen con base en diferentes contextos, y de manera indirecta. Debido a la pertinencia de estas categorías o funciones encontradas, se realizan varios ciclos de revisión documental presente en cada grupo de RTI para identificar aquellos aspectos que las relacionan con alguna categoría específica.

La figura 18 muestra el proceso, que después de varios ciclos de análisis y síntesis realizada de las categorías y funciones que dominan las RTI, se correlacionaron junto con las definiciones y grupos creados, para identificar qué función define mejor cada grupo, y de esta forma extender y consolidar la información del modelo de clasificación propuesto.

Es de aclarar, que a lo largo del artículo se presenta imágenes y esquemas que fortalecen la comprensión, identificación y apropiación de las diferentes RTI. Textos e imágenes se utilizan para ejemplificar la teoría encontrada sobre las relaciones texto-imagen, y fueron creadas específicamente para este estudio. Las imágenes que no son de autoría propia llevan sus respectivas fuentes bibliográficas. 
Finalmente, se realizó el modelo de visualización el cual permite ubicar cada RTI en un espacio 3D bajo las categorías establecidas a lo largo del estudio. Dicho modelo tiene una representación cónica invertida, emulando el modelo de color HSV.

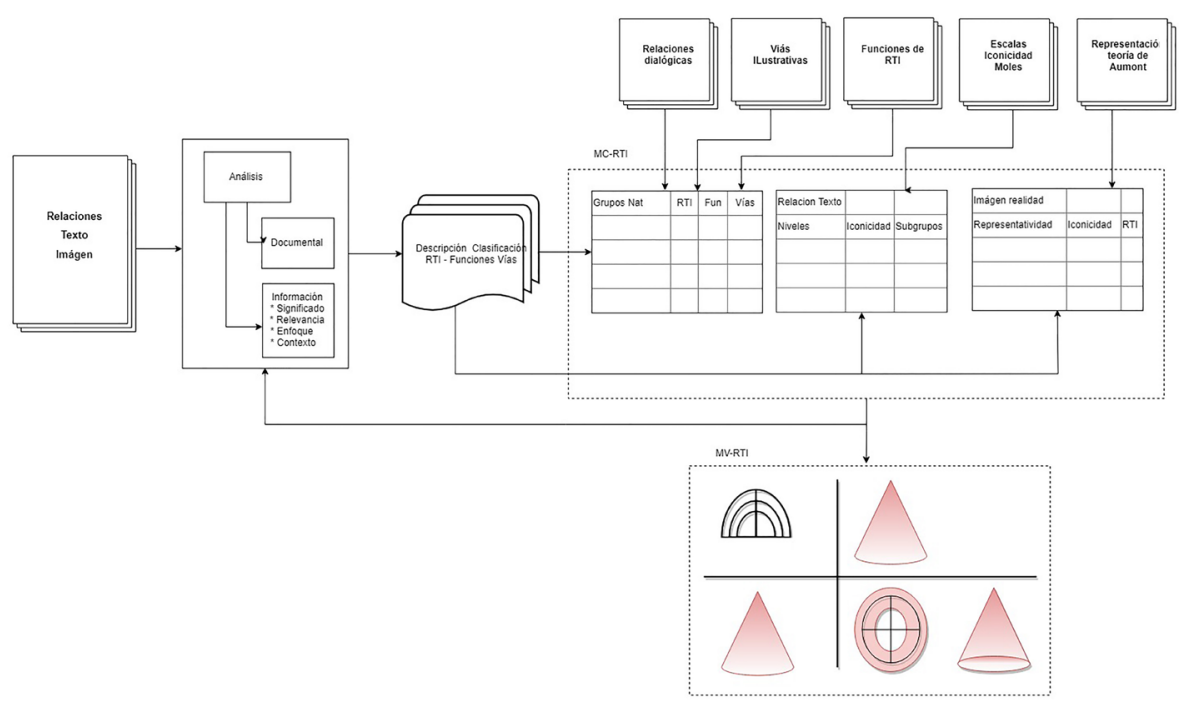

Figura 18. Modelo metodológico

\section{Resultados y análisis}

En el mundo de las RTI, existen muchas equivalencias entre las diferentes teorías, y puede llegar a pensarse que una es resultado de la evolución normal, como es el caso de las relaciones presentadas en los cómics, o la gran similitud entre las relaciones de proyección por locución y montaje, el valor de signo con el mensaje semiótico. Es por eso que las relaciones presentadas anteriormente, 
aunque provienen de diferentes autores y contextos, todas pueden relacionarse entre sí y organizarse de manera estructurada conformando un todo, que a continuación se presenta como el modelo de clasificación MC-RTI, apoyado por los intervalos de representatividad de relación con texto e intervalos de representación de imagen-realidad, y se robustece con un modelo de visualización 3D MV-RTI, todo bajo la lupa y organización que se presenta en el esquema de visualización 2D de las RTI.

Modelo de clasificación. La clasificación de la RTI, según su naturaleza y similitud en su definición, permite identificar la identidad de la relación con el fin de condensar el significado de los grupos de RTI. La tabla 02 presenta el modelo de clasificación MC-RTI, el cual agrupa las RTI según su naturaleza, en 12 categorías creadas con base en el análisis de información. Cada categoría contiene diferentes RTI identificadas con letras, que representan subgrupos, de acuerdo con las características y similitud. Adicionalmente, cada categoría de RTI tiene las funciones y vías empáticas asociadas, que favorecen una mayor comprensión. Esta clasificación muestra que las RTI se identifican por su naturaleza y su función, y establece un orden con el fin de evitar la proliferación de RTI. 
Tabla 02. Modelo de clasificación RTI.

\begin{tabular}{|c|c|c|c|c|c|}
\hline Grupo por naturaleza & $\begin{array}{l}\text { Subgrupo } \\
\text { identificador }\end{array}$ & RTI & Función & Vías ilustrativas & Tipo de iconicidad \\
\hline \multirow{2}{*}{ Representatividad } & \multirow{2}{*}{ A } & Valor de representación & Interpretación & \multirow{2}{*}{ Vía objetiva } & \multirow{2}{*}{ Representación } \\
\hline & & Duo específica & Reiteración & & \\
\hline \multirow{3}{*}{ Abstracción } & B & Valor de símbolo & Interpretación & \multirow{3}{*}{$\begin{array}{l}\text { Vía empática } \\
\text { ingeniosa }\end{array}$} & Descripción \\
\hline & $\mathrm{C}$ & Valor de signo & Condensado & & Abstracción \\
\hline & & Mensaje semiótico & Explicación & & \\
\hline \multirow{9}{*}{ Dependencia } & & Dependencia & \multirow{4}{*}{ Organización } & & \\
\hline & $\mathrm{D}$ & Anclaje & & & \\
\hline & $E$ & Desigualdad & & & \\
\hline & $\mathrm{F}$ & Subordinación & & & \\
\hline & \multirow{3}{*}{ G } & Narrativa & & & \\
\hline & & Simbiosis & & & \\
\hline & & Interdependencia & Desarrollo & & \\
\hline & \multirow[t]{2}{*}{$\mathrm{H}$} & Relevo & & & \\
\hline & & Combinación alternante & & & \\
\hline \multirow{4}{*}{ Independencia } & I & Imagen-específica & \multirow{4}{*}{ Decorativa } & & \\
\hline & $J$ & Palabra específica & & & \\
\hline & K & Igualdad & & & \\
\hline & $\mathrm{L}$ & Vasallaje & & & \\
\hline \multirow{2}{*}{ Generalidad } & M & Ejemplificación & \multirow{2}{*}{ Desarrollo } & & Indiferentes \\
\hline & $\mathrm{N}$ & Exposición & & & \\
\hline \multirow{3}{*}{ Relación ajena } & $\mathrm{O}$ & Complemento (LS) & \multirow{3}{*}{ Interpretación } & & \\
\hline & $\mathrm{P}$ & Divergencia & & & \\
\hline & & Combinación paralela & & & \\
\hline \multirow{3}{*}{ Ampliación } & Q & Combinación aditiva & \multirow{3}{*}{$\begin{array}{l}\text { Organización } \\
\text { Desarrollo }\end{array}$} & & \\
\hline & & Ampliación & & & \\
\hline & $\mathrm{R}$ & Extensión & & & \\
\hline \multirow{5}{*}{ Texto en la imagen } & & Texto explícito & & & \\
\hline & S & Locución & & & \\
\hline & & Montaje & & & \\
\hline & $\mathrm{T}$ & Texto implícito & & & \\
\hline & & Complemento (E) & & & \\
\hline \multirow{2}{*}{ Interpretación del autor } & \multirow{2}{*}{ U } & \multirow{2}{*}{ Clarificación } & Vía empatía afectiva & & \\
\hline & & & Vía subjetiva & & \\
\hline \multirow{3}{*}{ Ficción } & \multirow{3}{*}{ V } & & Reiteración & & \\
\hline & & Ficción & Organización & & Descripción \\
\hline & & & Desarrollo & & \\
\hline \multirow{2}{*}{ Indefinidas } & \multirow{2}{*}{ W } & Mensaje morfológico & Interpretación & & \\
\hline & & Significado & Desarrollo & & \\
\hline Ilustración & $X$ & & & & \\
\hline
\end{tabular}


Representatividad de relación con texto. Cuando una imagen describe fielmente el texto, se habla de un alto nivel de representación. Por el contrario, si una imagen no tiene una representación formal del texto, tiene un alto nivel de abstracción.

La abstracción no siempre es artística, sino también conceptual. Como se vio en el artículo, algunas RTI ejemplifican imágenes que se basan de signos y símbolos abstractos para dar información, los cuales engloban conceptos técnicos cuyo análisis e interpretación depende de un conocimiento previo.

Lo anterior permite realizar una clasificación, tabla 03, de intervalos de representatividad basado en Moles, contextualizados en el ámbito de la relación con el texto, agrupados en forma de intervalos que amplían la posibilidad de correspondencia por parte de algunas relaciones. Todo con relación a los elementos similares que podrían ser agrupados, y así formar intervalos dentro de la escala propuesta. Para esta nueva clasificación se excluyen el primero y último nivel de la escala de Moles, debido a que no hacen referencia a representaciones visuales de la realidad.

Esta clasificación por intervalos de representatividad de palabra-concepto concentra los niveles de iconicidad de acuerdo con sus características básicas que van más allá de la escala propuesta por Moles.

Tabla 03. Tipo de iconicidad con relación al texto.

\begin{tabular}{lll}
\hline Intervalo & Tipo de iconicidad & Subgrupo de RTI \\
\hline $9-8$ & De representación & $\mathrm{A}, \mathrm{X}, \mathrm{J}$ \\
\hline $7-6$ & Descripción & $\mathrm{V}$ \\
\hline $5-4$ & Esquematización & $\mathrm{W}$ \\
\hline $3-2$ & Abstracción & $\mathrm{B}, \mathrm{C}$ \\
\hline 1 & Indiferentes & $\mathrm{D}, \mathrm{E}, \mathrm{F}, \mathrm{G}, \mathrm{H}, \mathrm{I}, \mathrm{I}, \mathrm{K}, \mathrm{L}, \mathrm{M}, \mathrm{N}$ \\
\hline
\end{tabular}


Representatividad de imagen-realidad. De acuerdo con el análisis documental previo, se encontró que un elemento característico de muchas RTI es el nivel de representatividad de la imagen con relación al texto, congruente con el valor de representatividad propuesto por Aumont (1992). La tabla 04 presenta una nueva clasificación de elementos de los niveles de iconicidad presentados por Moles, según su nivel representatividad y su nivel de abstracción, de acuerdo con el nivel de congruencia de la imagen con la realidad y el texto que representa.

La clasificación por intervalos de representatividad de imagen - realidad, reúne los niveles de iconicidad de Moles, de acuerdo con las características básicas de la representación de la realidad.

Tabla 04. Intervalos de representación.

\begin{tabular}{|c|c|c|}
\hline Nivel de Representatividad & Nivel de iconicidad de Moles & $\begin{array}{l}\text { Subgrupo } \\
\text { RTI }\end{array}$ \\
\hline Alta & $\begin{array}{l}\text { Modelo a escala } \\
\text { Escultura, modelo tridimensional realista } \\
\text { Representación anamórfica } \\
\text { Esquema anatómico o de construcción } \\
\text { Fotografía o proyección realista sobre un plano } \\
\text { Vista en sección o alzado }\end{array}$ & $A, J, V$ \\
\hline Media & $\begin{array}{l}\text { Subjetiva } \\
\text { Dibujo, fotografía de alto contraste }\end{array}$ & $\mathrm{X}, \mathrm{W}$ \\
\hline Baja & $\begin{array}{l}\text { Artística } \\
\text { Arte abstracto } \\
\text { Simbolismo } \\
\text { Semiótica } \\
\text { Conceptual } \\
\text { Esquema de espacios complejos } \\
\text { Esquema de vectores en espacios abstractos }\end{array}$ & $\mathrm{B}, \mathrm{C}, \mathrm{O}, \mathrm{P}$ \\
\hline Nula & $\begin{array}{l}\text { Las relaciones de esta categoría son independientes a su nivel de } \\
\text { representatividad con el texto }\end{array}$ & $\mathrm{D}, \mathrm{E}, \mathrm{F}, \mathrm{G}, \mathrm{H}, \mathrm{I}, \mathrm{K}$ \\
\hline
\end{tabular}


Con el objetivo de formalizar el estudio anterior, y esquematizar la categorización realizada del MC-RTI, se propone un modelo de visualización tridimensional (MV-RTI), que representa las RTI como elementos conectados por las diferentes dimensiones del modelo.

Modelo de visualización 3D. El propósito de la visualización es precisar espacialmente la información del MC-RTI. El modelo de visualización MVRTI utiliza un espacio 3D de forma cónica invertida que permite ubicar de manera formal cada categoría, según las características halladas. Se establecen parámetros con base en los niveles de iconicidad de Moles, al cual se le hacen dos miradas, una con relación al texto y la otra entre imagen realidad, que sirven para establecer los ejes del modelo. Se pasa de 12 niveles de Moles a 6 de relación con texto, y a 4 intervalos de representatividad.

Las dos miradas se utilizan para la conformación de los ejes del modelo, radio y altura, en un cono invertido. El radio constituye los niveles con relación al texto, a menor radio mayor representatividad, a mayor radio menor representatividad. El eje constituye intervalos de representación imagen realidad, con escala desde nulo hasta alto.

La base tiene dispuesto los grupos por naturaleza, ubicados de manera complementaria por definición, es decir, ubicados en posición opuesta, realizando una analogía con el círculo cromático, y junto a aquellos con los que presenta similitudes, es decir, ubicados de manera adyacente. Además, las funciones RTI se exponen como mapas de colores asociados a cada grupo. La visualización permite ubicar e identificar de manera gráfica en el lugar que le corresponde a cada RTI en el modelo propuesto. 

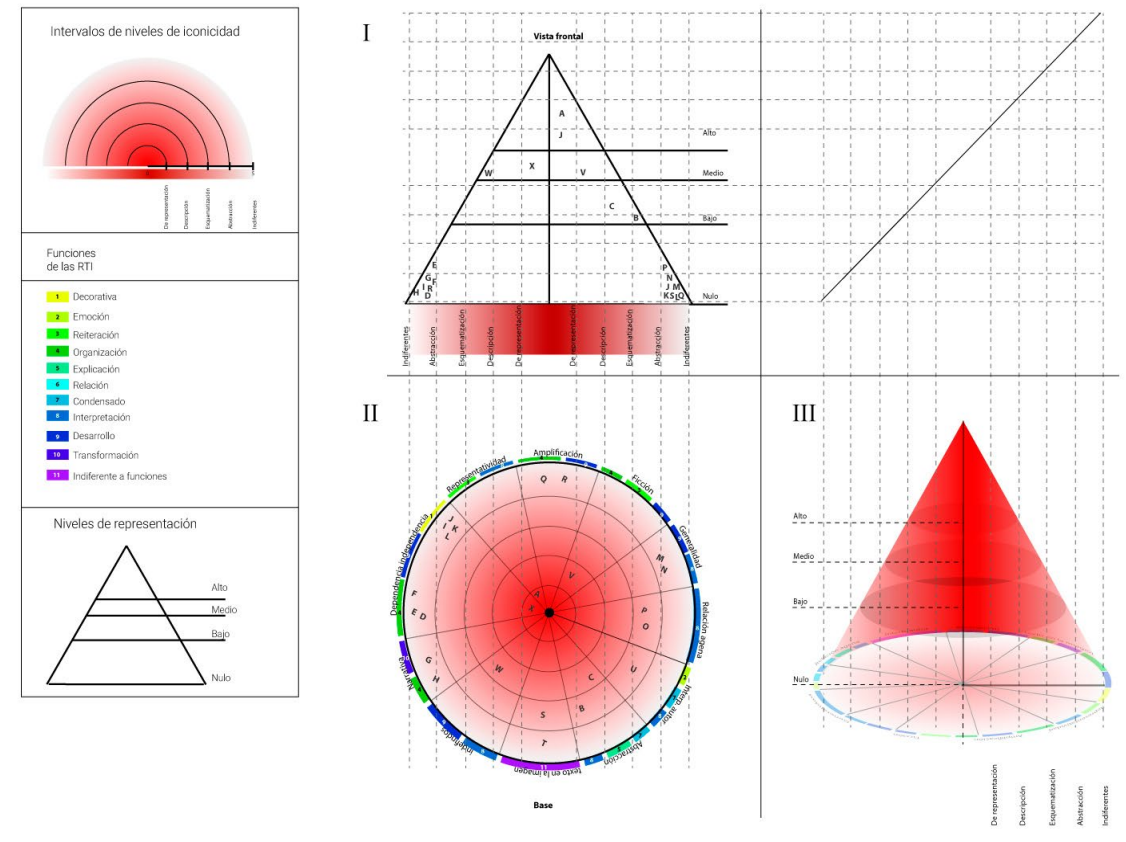

Figura 19. Modelo de visualización 3D

Esquema de visualización 2D. El propósito de la visualización 2D consiste en tener una visión global jerárquica de cada una de las RTI. El esquema de representación 2D (figura 20) sale del análisis documental que muestra cómo las ilustraciones tienen funciones, manejan vías ilustrativas y generan relaciones entre el texto y la imagen. El diagrama muestra la relación de jerarquía y además conecta aquellas que se complementan o son similares. Finalmente, permite observar la proliferación de RTI. 
Revista KEPES, Año 16 No. 20, julio-diciembre de 2019, págs 283-343

336

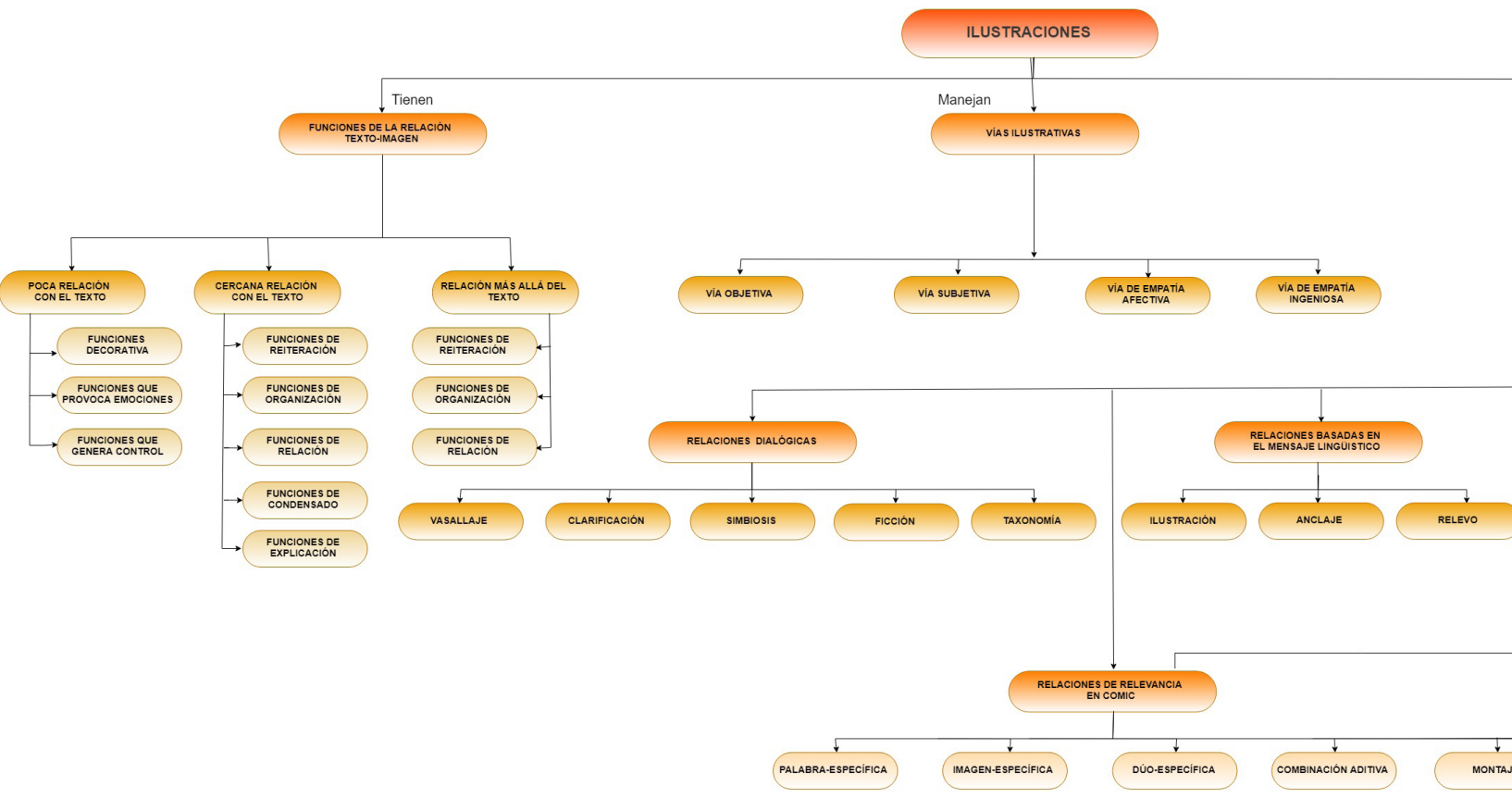




\section{Discusión}

Existe una gran cantidad de RTI debido a que diferentes autores proponen formas de clasificar las relaciones. La falta de estandarización en la creación de $\mathrm{RTI}$, conlleva a que surjan nuevas formas de relación de manera independiente y aislada. Por eso existen RTI que son semánticamente iguales, pero se categorizan diferente de acuerdo con la intención del autor y el contexto en el que se presente. Adicionalmente, debido a la cercanía semántica de algunas relaciones, es posible agruparlas, así como atribuirles diferentes funciones, niveles de representatividad y niveles de iconicidad para facilitar su uso y apropiación.

Asimismo, para facilitar la comprensión de imágenes y guiar al lector en su adecuada interpretación, muchos autores han identificado diferentes formas en las que texto e imagen conviven, y qué función cumple cada medio de acuerdo con el contexto en el que se presenten. Esta forma de relacionarse entre sí es de gran ayuda para evitar ambigüedad y transmitir mejor la información, pero no se tiene en cuenta una visión global del mundo de las RTI, que incluya la naturaleza, sus funciones y vías ilustrativas.

Por lo anterior, se analizan más de 50 tipos de RTI incluidas las funciones y vías ilustrativas, las cuales se organizan en 12 grupos que muestran la naturaleza de las RTI, percibida la ilustración como gran grupo que contiene y soporta la totalidad de las RTI. Cada grupo tiene uno o varios subgrupos para un total de 24, los cuales se caracterizan y precisan la clasificación, y sirven para la ubicación espacial en el modelo de visualización 3D.

La representación 3D facilita la ubicación espacial en su conjunto, y permite de una sola mirada identificar a qué categoría, función y vía ilustrativa está asociada la RTI. También, según la altura y distancia al eje se identifica que 
tanta representación de la realidad y relación con el texto presenta. Además, el modelo MV-RTI es un modelo escalable que permite agregar o desagregar relaciones de acuerdo con posibles cambios en MC-RTI basados en la inclusión de nuevas RTI.

Por otro lado, la representación 2D muestra la ubicación jerárquica que permite ubicar un nivel dentro del gran contexto de la RTI en el mundo de la ilustración.

Para ubicar en el modelo visual 3D una RTI nueva o existente, se recomienda identificar el tipo de función al que está asociada la RTI, tabla 02; seguidamente buscar el nivel de representatividad según la tabla 03, esto ubica la RTI en la base del modelo cuadrante 2. La ubicación en el eje que muestra la vista frontal, se debe identificar la representación en niveles de imagen de la RTI, tabla 03 y luego el nivel de iconicidad, tabla 02.

\section{Conclusiones}

- En conclusión, nuestro trabajo clasifica las RTI bajo un contexto de similitud por naturaleza con relación en las funciones y vías ilustrativas, formado un modelo basado en la representatividad y que es visualizado en 2D y 3D para facilitar la ubicación espacial y conceptual de cada RTI nueva o existente.

- El modelo de clasificación permite incluir todas las RTI en las categorías propuestas, y en caso de no poder ubicar una RTI, se encuentra la categoría de indefinidas, en la cual se puede situar. Por tanto, el modelo propuesto es un modelo que engloba, acoge y establece un orden que evita la proliferación de RTI. 
- La estructura del modelo de visualización 2D y 3D permiten ver la similitud y divergencia de una RTI con relación a las demás y del conjunto, por su ubicación espacial, en correlación según la naturaleza, sus funciones y vías ilustrativas.

- Los modelos de clasificación y visualización de RTI son herramientas útiles para la comprensión de su taxonomía, aprendizaje y apropiación, debido a que caracterizan similitudes semánticas, vínculos y relaciones entre RTI desde diferentes perspectivas.

\section{Agradecimientos}

Este trabajo es financiado con recursos de la Vicerrectoría de Investigaciones de la Universidad Militar Nueva Granada, en el proyecto INV-ING-1763, "Identificación de características de personajes a partir de una historia".

\section{Referencias}

Armida, P. (2013). Narrativa ilustrada: más allá del libro álbum y la novela gráfica. Reflexiones Marginales. Recuperado de http://reflexionesmarginales. com/3.0/category/22-literatura-infantil/22-articulos/

Aumont, J. (1992). La Imagen. Barcelona: Ediciones Paidós Ibérica.

Barthes, R. (1986). Retórica de la imagen. Lo obvio y lo obtuso. Paidós, Barcelona.

Chiuminatto, M. (2011). Relaciones texto-imagen en el libro álbum. Revista Universum, 1 (26), 59-77. DOI: dx.doi.org/10.4067/S071823762011000100004 
Domas, M. and Marsh, E. (2003). A taxonomy of relationships between images and text. Journal of Documentation, 59 (6), 647-672. DOI: doi. org/10.1108/00220410310506303

Durán, T. (2005). Ilustración, Comunicación, Aprendizaje. Sociedad Lectora y Educación, Ministerio de Educación y Formación Profesional, 239-253. Recuperado de http://www.educacionyfp.gob.es/revista-de-educacion/ numeros-revista-educacion/numeros-anteriores/2005/re2005/re2005-16. html DOI: 10.4438/1988-592X-0034-8082-RE

Fang, Z. (1996). Illustrations, Text, and the Child Reader: What are Pictures in Children's Storybooks for? Reading Horizons, 3, 37 (2), 130-141. Recuperado de https://scholarworks.wmich.edu/reading_horizons/vol37/iss2/3

Gubern, R. (1987). La mirada opulenta. Exploración de la iconosfera contemporánea. Barcelona: Gustavo Gili.

Lester, P. (2014). Visual Communication: Images with Messages. Boston: Wadsworth Cengage Learning.

Martinec, R \& Salway, A. (2011). A system for image-text relations in new (and old) media. DOI: doi.org/10.1177/1470357205055928

McCloud, S. (1993). Understanding the Comics. Nueva York: Kitchen Sink.

McCloud, S. (2006). Making Comics. Storytelling secrets of comics, manga and graphic novels. Nueva York: Harper.

Menza, A.E., Sierra, E.L., Rocha, C.A. y Sánchez, W.H. (2015). COPEM: Sistema de construcción de personajes basado en metadatos. Memorias Congreso Internacional Multimedia. Vol. 4. 43-52.

Menza, A.E., Sierra, E.L. y Sánchez, W.H. (2016). La ilustración: dilucidación y proceso creativo. Revista KEPES, 13, 265-296. DOI: 10.17151/ kepes.2016.13.13.12 
Mitchell, W.J. (2009). Teoría de la imagen. Madrid. Ediciones Akal, S.A.

Moles, A. (1976). Teoría de la información y percepción estética. Editorial Júcar, Gijón.

Pacheco, E. (2009). Los nuevos procesos de construcción de contenidos periodísticos. IS en la Red, 1. Recuperado de http://justo-sierra.com/ revista_jeroglifos/pdf/Art\%C3\%ACculo\%20Infograf\%C3\%ACa.pdf

Pimentel, L. (2003). Écfrasis y lecturas iconotextuales. Poligrafías. Recuperado de http://www.revistas.unam.mx/index.php/poligrafias/article/view/31343

Piñuel, J. (1999). Abraham A. Moles (1902-1992) y la teoría de la información. CIC, (4), UCM. Recuperado de https://revistas.ucm.es/index.php/CIYC/ article/view/CIYC9899110157A/7406

Rosero, J. (2010). Las cinco relaciones dialógicas entre el texto y la imagen dentro del álbum ilustrado, Colombia. Recuperado de http://www. anniemate.com/ilustradorescolombianos/documentos/index.html

Sánchez, J. (2006). Narrativa audiovisual. UOC (pp. 13-15).

Sanmiguel, D. (2000). Todo sobre la técnica de la ilustración. Barcelona: Parramón Ediciones.

Stein, D. and Thon, J.N. (2015). From Comic Strips to Graphic Novels: Contributions to the Theory and History of Graphic Narrative. Germany: Gruyter Publisher.

Sung M. (2013). De la narración literaria a la narración visual: Proyecto de ilustración. Proyecto de grado para maestría en Producción Artística, Universitat Politécnica De Valéncia Facultat De Belles Arts, Valencia.

Unsworth, L. (2006). 33 $3^{\text {rd }}$ International Systemic Functional Congress 2006. Image/text relations and intersemiosis: towards multimodal text description for multiliteracies education. University of New England, Armidale, 
Australia. Recuperado de http://www4.pucsp.br/isfc/proceedings/list_of_ all_articles.htm

Watzlawick, P. (1985). Teoría de la comunicación humana. Interacciones, Patologías y Paradojas. Barcelona: Editorial Herder.

Como citar: Menza, A.E., Rocha, C.A. y Sánchez, W.H. (2019). Modelo de clasificación y visualización de relaciones texto-imagen. Revista KEPES, 16 (20), 283-343. DOI: 10.17151/kepes.2019.16.20.12 